\title{
Neuropilin 2 Signaling Mediates Corticostriatal Transmission, Spine Maintenance, and Goal-Directed Learning in Mice
}

\author{
(D) Maxime Assous, ${ }^{1 *}$ Edward Martinez, ${ }^{2 \star}$ Carol Eisenberg, ${ }^{2}$ Fulva Shah, ${ }^{1}$ Aleksandra Kosc, ${ }^{3}$ Kristie Varghese, ${ }^{2}$ \\ Diego Espinoza, ${ }^{3}$ Shaznaan Bhimani, ${ }^{3}$ ㅇames M. Tepper, ${ }^{1}$ Michael W. Shiflett, ${ }^{3}$ and ${ }^{\circ}$ Tracy S. Tran ${ }^{2}$ \\ ${ }^{1}$ Center for Molecular and Behavioral Neuroscience, and Departments of ${ }^{2}$ Biological Sciences, and ${ }^{3}$ Psychology, Rutgers University, Newark, New Jersey 07102
}

The striatum represents the main input structure of the basal ganglia, receiving massive excitatory input from the cortex and the thalamus. The development and maintenance of cortical input to the striatum is crucial for all striatal function including many forms of sensorimotor integration, learning, and action control. The molecular mechanisms regulating the development and maintenance of corticostriatal synaptic transmission are unclear. Here we show that the guidance cue, Semaphorin $3 \mathrm{~F}$ and its receptor Neuropilin 2 (Nrp2), influence dendritic spine maintenance, corticostriatal short-term plasticity, and learning in adult male and female mice. We found that Nrp2 is enriched in adult layer V pyramidal neurons, corticostriatal terminals, and in developing and adult striatal spiny projection neurons (SPNs). Loss of Nrp2 increases SPN excitability and spine number, reduces short-term facilitation at corticostriatal synapses, and impairs goal-directed learning in an instrumental task. Acute deletion of $N r p 2$ selectively in adult layer $\mathrm{V}$ cortical neurons produces a similar increase in the number of dendritic spines and presynaptic modifications at the corticostriatal synapse in the $\mathrm{Nrp} 2^{-1-}$ mouse, but does not affect the intrinsic excitability of SPNs. Furthermore, conditional loss of Nrp2 impairs sensorimotor learning on the accelerating rotarod without affecting goal-directed instrumental learning. Collectively, our results identify Nrp2 signaling as essential for the development and maintenance of the corticostriatal pathway and may shed novel insights on neurodevelopmental disorders linked to the corticostriatal pathway and Semaphorin signaling.

Key words: cortical pyramidal neurons; neurodevelopment; rotarod; semaphorin signaling; short-term plasticity; striatum

Significance Statement

The corticostriatal pathway controls sensorimotor, learning, and action control behaviors and its dysregulation is linked to neurodevelopmental disorders, such as autism spectrum disorder (ASD). Here we demonstrate that Neuropilin 2 (Nrp2), a receptor for the axon guidance cue semaphorin $3 \mathrm{~F}$, has important and previously unappreciated functions in the development and adult maintenance of dendritic spines on striatal spiny projection neurons (SPNs), corticostriatal short-term plasticity, intrinsic physiological properties of SPNs, and learning in mice. Our findings, coupled with the association of Nrp2 with ASD in human populations, suggest that Nrp2 may play an important role in ASD pathophysiology. Overall, our work demonstrates Nrp2 to be a key regulator of corticostriatal development, maintenance, and function, and may lead to better understanding of neurodevelopmental disease mechanisms.

\section{Introduction}

The striatum constitutes the main input structure of the basal ganglia. It receives massive excitatory projections originating from essentially all regions of the cortex as well as multiple thalamic nuclei (Kemp and Powell, 1970; Buchwald et al., 1973; Smith et al., 2014). The major target of cortical input to the 
striatum is the dendritic spines of the GABAergic spiny projection neurons (SPNs), which constitute 95\% of striatal neurons (Gerfen and Surmeier, 2011). The corticostriatal pathway mostly originates from layer $\mathrm{V}$ of the cortex and to a lesser extent from layer III (McGeorge and Faull, 1989; Shepherd, 2013; Sohur et al., 2014). Corticostriatal projections in the adult animal are essential for the regulation of a wide range of behavioral and cognitive functions, and dysregulation of corticostriatal activity has been implicated in many neurodevelopmental and neuropsychiatric disorders (Pennartz et al., 2009; Balleine and O'Doherty, 2010; Shiflett and Balleine, 2011; Shepherd, 2013).

Many factors influence the organization and development of cortical projection neurons, including molecular guidance cues (Ding et al., 2011; Greig et al., 2013; Sohur et al., 2014). One such factor is the class 3 secreted semaphorins (Sema3s), a member of the semaphorin protein family that is essential for the appropriate elaboration of axons and dendrites during neural development (Mann et al., 2007; Tran et al., 2007; Pasterkamp and Giger, 2009; Yoshida, 2012). Sema3s use both Neuropilins (Nrps) and Plexins (Plxns) as their ligand binding and signal transducing receptor subunits, respectively, forming a receptor complex (Mann et al., 2007; Tran et al., 2007). In the developing mammalian nervous system, Sema3F operating through Neuropilin 2 (Nrp2)/PlxnA3 ligand receptor signaling has an important role in axon repulsion and in dendritic spine morphogenesis (Giger et al., 2000; Huber et al., 2005; Yaron et al., 2005; Tran et al., 2009). During mouse postnatal development, Sema3F regulates excitatory synapse formation in apical dendrites of layer $\mathrm{V}$ pyramidal neurons, and loss of this signaling increases apical dendrite spine density and the excitability of these neurons (Tran et al., 2009; Demyanenko et al., 2014). In humans, semaphorin and plexin gene variants are associated with a number of neurodevelopmental disorders, including autism spectrum disorder (Wu et al., 2007; Fujii et al., 2011; Cheng et al., 2013; Mosca-Boidron et al., 2016; Kim et al., 2017).

Semaphorins may have an important role in corticostriatal pathway development and maintenance. Indeed, the related semaphorin Sema3E is present in the developing striatum and signals through PlexinD1 to establish thalamostriatal synapses on direct pathway SPNs (Ding et al., 2011). Furthermore, semaphorins have a recently described role in various forms of adult synaptic plasticity (Orr et al., 2017; Wang et al., 2017). Finally, semaphorin signaling could influence corticostriatal synapses by altering excitatory synapse formation in apical dendrites of layer V neurons, which may have downstream effects on the corticostriatal synapse (Kozorovitskiy et al., 2012; Peixoto et al., 2016).

Here, we investigated the role of Sema3F-Nrp2 signaling in corticostriatal plasticity and related behaviors using either Nrp2-null [knock-out (KO)] mice or mice in which Nrp2 was conditionally deleted from adult layer V neurons [Nrp2flox;Etv1CreERT2 conditional KO (CKO)]. In these mice, we analyzed the expression profile of Nrp2 in layer $\mathrm{V}$ cortical neurons and corticostriatal axons as well as in SPNs. Further, we tested whether global deletion of Nrp2 or conditional deletion in layer V cortical neurons altered corticostriatal short-term plasticity. Finally, we examined these mice in an instrumental learning task and the accelerating rotarod, behaviors known to depend on the corticostriatal pathway (Costa et al., 2004; Costa, 2007; Yin et al., 2009; Shiflett et al., 2015). Altogether, our results demonstrate the importance of Sema3F-Nrp2 signaling in corticostriatal physiology and related behaviors.

\section{Materials and Methods}

\section{Animals}

The expression patterns and developmental phenotypes of the Neuropilin 2 (Nrp2) knock-out mice have been previously described in detail (Giger et al., 2000). The Nrp2 floxed mice were previously described (Walz et al., 2002), whereafter the Cre recombination part of exon 1 including the start codon is removed, and tauGFP- $\mathrm{pA}^{+}$is placed immediately downstream of the Nrp2 promoter. The Nrp2 floxed mice were crossed with the Etv1-CreERT2 (stock \#013048, The Jackson Laboratory) mice where Cre recombinase was shown to be expressed specifically in layer V cortical neurons (Harris et al., 2014). Some Nrp2f/f;Etv1 ${ }^{+} / \mathrm{Cre}$ progenies were crossed with the Thy1-GFP reporter (M line; stock \#007788, The Jackson Laboratory) to specifically detect GFP expression in cortical layer V pyramidal neurons (Feng et al., 2000). Mice used in this study were backcrossed for at least 10 generations to the C57BL/6NTac background strain. Only males were used for behavioral testing. During behavioral testing procedures, mice were placed on a restricted food diet of $\sim 5 \mathrm{~g}$ of standard chow (Purina) given in their home cage each day after behavior procedures were complete. Animals were weighed daily, and their body weights during the procedure were within $85-90 \%$ of their free-feeding weight. All procedures followed the NIH Guide to Care and Use of Laboratory Animals and were approved by the Rutgers Institutional Animal Care and Use Committee.

\section{Immunocytochemistry}

All adult (3-9 months) WT mice were subjected to transcardial perfusion with $4 \%$ paraformaldehyde (PFA) in PBS, brains removed, and postfixed for $1 \mathrm{~h}$ fixation with 4\% PFA. For anti-Nrp2 labeling, tissue was prepared as previously described (Schneider Gasser et al., 2006). Briefly, brains from WT and $\mathrm{Nrp2}^{-1-}$ mice were dissected and snap frozen using isopentane prechilled with dry ice. Fresh frozen brains were sectioned on a cryostat at $20 \mu \mathrm{m}$ along the coronal plane. Subsequently, sections were fixed by brief immersion in 4\% PFA for $2 \mathrm{~min}$. Sections were processed for immunocytochemistry as previously described (Tran et al., 2013), with the following modifications. After PBS wash, the sections were incubated in $0.8 \%$ Triton X-100 in PBS for 10 min followed by three washes of 5 min each in PBS. Next, the sections were incubated in blocking solution (5\% normal donkey serum and $0.1 \%$ Triton X-100 in PBS) for $1 \mathrm{~h}$. After blocking, the sections were incubated with primary antibodies overnight at $4^{\circ} \mathrm{C}$. The next day, the sections were washed three times for 10 min each in PBS, followed by secondary antibody incubation for $2 \mathrm{~h}$ in the dark. Finally, the sections were washed four times for 10 min each in PBS, slide mounted with Vectashield antifade mounting medium with DAPI (Vector Laboratories). The primary antibodies used were as follows: rabbit monoclonal anti-Nrp2 (1:500; catalog \#3366, Cell Signaling Technology; RRID:AB_2155250); goat polyclonal anti-Nrp2 $(5 \mu \mathrm{g} / \mathrm{ml}$; R\&D Systems); rabbit polyclonal anti-Darpp-32 (1:400; catalog \#2306, Cell Signaling Technology; RRID:AB_823479); guinea pig polyclonal anti-Vglut1 (1:1000; Millipore); chicken polyclonal anti-GFP (1:1000; Aves Laboratories); and for visualization, Alexa Fluor 488 or Alexa Fluor 568 (1:500; Life Technologies); Cy5 (1:500; Jackson ImmunoResearch).

\section{Data analysis and photodocumentation}

All immunocytochemically processed brain sections were analyzed using the Zen software (Zeiss) and Zeiss 510 LSC Confocal System, and representative nonoverlapping fields were imaged. Compiled $z$-stack images were exported as tif files. Images were captured with a Plan-Apochromat $63 \times / 1.40$ numerical aperture (NA) oil-immersion objective for high magnification, a Plan-Apochromat $20 \times / 0.8$ NA for lower magnification, and the following laser lines: 405, 488, 543, and $633 \mathrm{~nm}$.

\section{Preparation of brain slices for electrophysiology}

Mice aged 3-6 months were deeply anesthetized with a mixture of ketamine/xylazine $(80 / 20 \mathrm{mg} / \mathrm{kg})$ and transcardially perfused with ice-cold $\mathrm{N}$-methyl D-glucamine (NMDG)-based solution containing the following (in mM): 103.0 NMDG, $2.5 \mathrm{KCl}, 1.2 \mathrm{NaH}_{2} \mathrm{PO}_{4}, 30.0 \mathrm{NaHCO}_{3}, 20.0$ HEPES, 25.0 glucose, $101.0 \mathrm{HCl}, 10.0 \mathrm{MgSO}_{4}, 2.0$ thiourea, 3.0 sodium pyruvate, $12.0 \mathrm{~N}$-acetyl cysteine, and $0.5 \mathrm{CaCl}_{2}$, saturated with $95 \% \mathrm{O}_{2}$ and $5 \% \mathrm{CO}_{2}, \mathrm{pH} 7.2-7.4$ as previously described (Assous et al., 2017). 
After decapitation, the brain was quickly removed and transferred into a beaker containing the ice-cold oxygenated NMDG-based solution and trimmed to a block containing the striatum. Coronal or oblique parahorizontal $300 \mu \mathrm{m}$ sections were cut in the same medium using a Vibratome 3000 and immediately transferred to an oxygenated NMDGbased solution at $35^{\circ} \mathrm{C}$ for $5 \mathrm{~min}$, after which they were transferred to oxygenated normal Ringer's solution at $25^{\circ} \mathrm{C}$ until placed in the recording chamber that was constantly perfused $(2-4 \mathrm{ml} / \mathrm{min})$ with oxygenated Ringer's solution at $32-34^{\circ} \mathrm{C}$.

\section{Differential interference contrast imaging and recording}

Slices were visualized under infrared-differential interference contrast microscopy with a digital frame transfer camera (Cooke SensiCam, PCO) mounted on an Olympus BX50-WI epifluorescence microscope with a $40 \times$ long-working distance water-immersion lens.

Micropipettes for whole-cell recording were constructed from $1.2 \mathrm{~mm}$ outer diameter borosilicate pipettes on a Narishige PP-83 vertical puller. The standard internal solution for whole-cell current-clamp recording was as follows (in mM): $130 \mathrm{~K}$-gluconate, $10 \mathrm{KCl}, 2 \mathrm{MgCl}_{2}, 10 \mathrm{HEPES}, 4$ $\mathrm{Na}_{2} \mathrm{ATP}, 0.4 \mathrm{Na}_{2} \mathrm{GTP}$, and plus $0.1-0.3 \%$ biocytin, $\mathrm{pH}$ 7.3. These pipettes had a DC impedance of 3-4 M $\Omega$. Membrane currents and potentials were recorded using an Axoclamp 700B amplifier (Molecular Devices). Recordings were digitized at $20 \mathrm{kHz}$ with a CED Micro 1401 Mk II and a PC running Signal, version 5 (Cambridge Electronic Design). Sweeps were run at $20 \mathrm{~s}$ intervals.

Stimulating electrodes consisted of bipolar enamel/nylon-coated 100$\mu \mathrm{m}$-diameter stainless steel wires (California Fine Wire). For cortical stimulation, the electrodes were placed onto the surface of the corpus callosum. Stimuli consisted of single square-wave pulses (typically, 0.01-1 mA, $0.3 \mathrm{~ms}$ duration). For paired-pulse ratio experiments, brief trains consisting of two pulses delivered at $5-50 \mathrm{~Hz}$ were generated.

\section{Biocytin histochemistry}

At the completion of the experiments, slices containing biocytin-injected neurons were fixed by immersion in $4 \% \mathrm{PFA} / 15 \%$ picric acid in $\mathrm{PBS}$ and stored overnight in this fixative solution at $4^{\circ} \mathrm{C}$ before washes in PBS. The sections were washed three times for $10 \mathrm{~min}$ each in $0.1 \mathrm{M}$ phosphate buffer (PB) followed by $10 \%$ methanol and $3 \% \mathrm{H}_{2} \mathrm{O}_{2}$ for 15 min. After three washes for $10 \mathrm{~min}$ each in $0.1 \mathrm{M}$ PBS, the sections were incubated with avidin-biotin peroxidase complex (1:200; Vector Laboratories) and $0.1 \%$ Triton X-100 overnight at $4^{\circ} \mathrm{C}$. After washing six times for $10 \mathrm{~min}$ each in $0.1 \mathrm{M} \mathrm{PB}$, the sections were reacted with diaminobenzidine (DAB; $0.025 \%)$ and $\mathrm{H}_{2} \mathrm{O}_{2}(0.0008 \%)$ in PB. Nickel intensification was used (2.5 mm nickel ammonium sulfate and $7 \mathrm{~mm}$ ammonium chloride in the DAB and $\mathrm{H}_{2} \mathrm{O}_{2}$ incubation). The sections were then postfixed in $\mathrm{OsO}_{4}(0.1 \%$ in $\mathrm{PB}$ ) for $30 \mathrm{~min}$, dehydrated through a graded series of ethanol, followed by propylene oxide, and infiltrated overnight with a mixture of propylene oxide and epoxy resin (Durcupan, Fluka Chemie). The sections were then transferred to fresh resin mixture for several hours and flat embedded between glass slides and coverslips, and cured at $60^{\circ} \mathrm{C}$ for $24 \mathrm{~h}$.

\section{$3 D$ reconstruction of SPNs}

For quantitative comparison of the dendritic fields of control and transgenic SPNs, four well filled biocytin-injected SPNs from $\mathrm{Nrp}^{-1-}$ and WT mice were selected for complete $3 \mathrm{D}$ reconstruction and analysis by Neurolucida 2007.2 (MBF Bioscience). Neurons were traced at 40X (BX50, Olympus), and Sholl plots were created and quantified with Neurolucida as previously described (Assous et al., 2018).

\section{Dendritic spine quantifications}

SPNs labeled with biocytin were photographed with a Zeiss Axiovert 200M Inverted Microscope with a $40 \times$ objective, saved as compiled $z$-stack images and exported as tif files to ImageJ for quantification of individual spines. All spines located between 50 and $100 \mu \mathrm{m}$ from the cell soma on three randomly selected dendrites of each SPN were counted, and the average number of spines per $50 \mu \mathrm{m}$ of dendritic length were computed. This location was selected because the peak spine density in rodents occurs at $\sim 60 \mu \mathrm{m}$ from the soma (Wilson, 1993). At least 8-11 biocytin-labeled SPNs per genotype were counted and 4 animals per genotype (unpaired $t$ test). Spine density (spines per micrometer) along Thy1-GFP $P^{+}$-tagged layer $\mathrm{V}$ pyramidal neurons in adult brains treated with tamoxifen (TM) at 4-6 months of age were imaged in the coronal plane and quantified using the following parameters: proximal to soma was defined as the first $45 \mu \mathrm{m}$. The number of spines were scored by counting spines along a $45 \mu \mathrm{m}$ segment of the apical dendrite. The middle regions were defined as $45-90 \mu \mathrm{m}$ from the soma. The number of spines was scored by counting spines along this $45 \mu \mathrm{m}$ segment of the apical dendrite. A total of 80 layer $\mathrm{V}$ pyramidal neurons were scored for each of $\mathrm{Nrp} 2^{f / f}$;Etv1-CreER ${ }^{+}$and littermate controls; 4 animals were used per genotype. Littermate control genotypes include the following: Nrp2 $2^{\text {fl/f }} ; E t v 1^{+/+} ; T h y 1-G F P^{+}, N r p 2^{+/ / f} ; E t v 1^{+/+}$; Thy1-GFP $P^{+}$, and Nrp2 $2^{+/ / f} ; E t v 1^{+/ C r e} ;$ Thy1-GFP ${ }^{+}$.

\section{Behavioral procedures}

Instrumental behavior. Mice were tested in four identical operant conditioning chambers (Med Associates). Each operant conditioning chamber measured $15.9 \times 14.0 \times 12.7 \mathrm{~cm}$ (width $\times$ height $\times$ depth) and was constructed of stainless steel and clear plastic walls and a stainless steel grid floor. A food cup with infrared detectors was centered on one wall with retractable levers situated to the left and right of the food cup. Responses on one lever caused delivery of a single $20 \mathrm{mg}$ grain-based chocolate-flavored food pellet (Bio-Serv) into the food cup from a dispenser mounted outside the operant conditioning chamber. A single stimulus light located above the lever illuminated for $2 \mathrm{~s}$ during food pellet delivery. A $28 \mathrm{~V}$ light was located on the opposite wall from the food cup and illuminated the operant conditioning chamber during behavioral procedures. Each operant conditioning chamber was housed in a sound-attenuating shell and equipped with a ventilation fan that was activated during behavioral procedures. Control over the operant conditioning chambers was enabled by a PC operating through an interface. Operant conditioning chamber operation and data collection were performed with Med Associates proprietary software (Med-PC IV).

Behavioral procedures commenced after 1 week of food restriction. Mice were habituated to the operant conditioning chamber in one 15 min session, which was followed the next day by a 20 min session in which food pellets were dispensed on a random-time $60 \mathrm{~s}$ schedule accompanied by $2 \mathrm{~s}$ illumination of the stimulus light. The levers were withdrawn during this phase. The following day, mice began daily instrumental training sessions. During each session, a single lever was inserted into the operant conditioning chamber, and responses on the lever delivered a food pellet. For the first two sessions, each response resulted in pellet delivery and illumination of the stimulus light. For the remaining eight sessions, outcomes were delivered according to a variable ratio schedule, which required, on average, 7.5 responses to issue pellet delivery and illuminate the stimulus light. We used this training schedule because it has been shown to maintain goal-directed responding (Adams and Dickinson, 1981)

Following instrumental conditioning, mice underwent a selective satiety-induced outcome devaluation test. Mice were placed in individual cages identical to their home cages with a bowl that contained $10 \mathrm{~g}$ of food pellets. The bowl contained either the same flavor of food pellets as the instrumental outcome or an alternative flavor. After $1 \mathrm{~h}$, mice were placed in the operant conditioning chamber, and the lever was inserted for a 10 min extinction test. No pellets or stimulus lights were delivered during the test. The test was repeated the following day with the opposite type of food pellet from the first test serving as the devalued outcome.

Open field. The open field apparatus measured $40 \times 40 \mathrm{~cm}$ and was constructed of opaque gray plastic with a solid metal base (Stoelting). The apparatus had overhead lighting, and the illumination at the center of the base was $\sim 400$ lumens. Mice were placed in the center of the open field and removed after $20 \mathrm{~min}$. The test was conducted twice, once per day for 2 consecutive days, and the average of the two sessions was used for statistical analysis. A camera (60 fps; Ace, Basler) mounted above the open field was used to record behavior during the test session. The distance traveled and time spent in center zone $(20 \times 20$ $\mathrm{cm}$ ) during the test was calculated using tracking software (EthoVision version 11.5, Noldus). 
Elevated zero maze. The elevated zero maze (Stoelting) is a circular elevated track $50 \mathrm{~cm}$ in diameter. The track lane is $5 \mathrm{~cm}$ in width. The track is raised $50 \mathrm{~cm}$ from the floor. One-half of the track is enclosed in walls that are $15 \mathrm{~cm}$ in height. The track and walls are constructed of opaque material. During the test trial, a mouse was placed in an enclosed portion of the maze and allowed to freely explore. After $5 \mathrm{~min}$, the mouse was removed. If a mouse fell from the maze in the first $2 \mathrm{~min}$ of the trial, then the trial was repeated; otherwise, the trial was aborted. A video camera mounted above the maze captured the behavior of the mouse during the trial. Noldus EthoVision was used to track the position of the mouse during the trial.

Accelerating rotarod. The single-lane rotarod (Med Associates) consisted of a 3.18 -cm-diameter grooved plastic spindle raised $30 \mathrm{~cm}$ from the base of the apparatus. Mice were placed on the spindle, which linearly accelerated from 4 to $40 \mathrm{rpm}$ over $2 \mathrm{~min}$. The trial ended when the mouse fell off the spindle, made one complete revolution while gripping the spindle, or $5 \mathrm{~min}$ had elapsed. Each mouse received 5 consecutive trials per day for $2 \mathrm{~d}$.

\section{Experimental design and statistical analyses}

For immunocytochemistry experiments, a total of 16 animals were used: $3 \mathrm{Nrp} 2 \mathrm{KO}, 5$ wild-type (WT; +/+), and 4 Nrp2f/f;Etv1+/Cre; Thy1$G F P^{+}(\mathrm{CKO})$ with TM treatment between 4 and 6 months $(\mathrm{CKO}+\mathrm{TM})$ and 4 control + TM mice. Genotypes for control mice were as follows: Nrp2f/f;Etv1 ${ }^{+/+}$; Thy1-GFP ${ }^{+}, \mathrm{Nrp2}^{+} / f ; E t v 1^{+/+} ; \mathrm{Th} y 1-\mathrm{GFP}^{+}$, and $\mathrm{Nrp2}^{+} / f$; $\mathrm{Evt1}^{+} / \mathrm{Cre}$; Thy1-GFP ${ }^{+}$.

For spine density and Sholl analysis of SPNs, a total of eight animals were used. Four Nrp2 KO and $4 \mathrm{WT}(+/+), 11 \mathrm{KO}$ and 8 WT biocytinfilled SPNs were scored for spine density and unpaired $t$ test was used for statistical analysis (see Results for $t$ and $p$ values). For Sholl analysis, a total of eight random biocytin-filled SPNs (four per genotype) from the same WT and KO animals used for spine density analysis were reconstructed, and an unpaired $t$ test was used for statistical analysis (see Results and figure legends for $t$ and $p$ values). For spine density measurments in layer $\mathrm{V}$ cortical neurons in $\mathrm{CKO}, 4 \mathrm{Nrp} 2 \mathrm{f} / \mathrm{f} ; \mathrm{Etv} 1^{+} / \mathrm{Cre}$; Thy1-GFP $P^{+}$treated with TM, and 4 control + TM (same genotypes as those animals used for immunocytochemistry) were used, a total of 80 layer $\mathrm{V}$ cortical neurons were scored, and an unpaired $t$ test was performed (see Results and figure legends for $t$ and $p$ values).

For the electrophysiological experiments, a total of 14 animals were used, as follows: $4 \mathrm{Nrp} 2 \mathrm{KO}, 4 \mathrm{WT}(+/+), 3 \mathrm{CKO}+\mathrm{TM}$, and 3 control + TM mice. For intrinsic properties of SPNs between WT and KO, 13-20 neurons/animal/genotype were recorded and averaged, and an unpaired $t$ test was performed. For corticostriatal short-term plasticity experiments, 14-22 SPNs were recorded and two-way ANOVA was performed. For intrinsic properties of SPNs in CKO versus control mice, we recorded between 14 and 17 SPNs per group for each electrophysiological measurement. For corticostriatal short-term plasticity experiments between CKO and control mice, 15-18 SPNs were recorded per condition per genotype, and a two-way ANOVA was performed (see Results for $p$ and $F$ values).

For the behavior experiments, a total of 46 male mice were used. For experiments involving $\mathrm{Nrp} 2 \mathrm{KOs}, 7 \mathrm{KOs}$ and $11 \mathrm{WT}$ controls were used. For CKOs, $14 \mathrm{CKO}+\mathrm{TM}$ and 14 control mice (which included the following littermate genotypes: $\mathrm{Nrp} 2^{+/+} ; \mathrm{Etv} 1^{+} / \mathrm{Cre}$ and $\mathrm{Nrp2^{+ }} / \mathrm{f} ; \mathrm{Etv} 1^{+} /$ $\mathrm{Cre})$ were used. Control mice were as follows: $\mathrm{Nrp2}^{+/+} ; \mathrm{Etv1} 1^{+} / \mathrm{Cre}$ and $\mathrm{Nrp}_{2} 2^{+} / \mathrm{f}$ Etv $1^{+} /$Cre with TM treatment or Nrp2f/f:Etv1 ${ }^{+} / \mathrm{Cre}$ with no tamoxifen treatment. Dependent behavioral measures were continuous, and included the instrumental response rate, the open field distance traveled, the time spent in open arms of the zero maze, and the latency to fall from the rotarod. For all experiments, genotype was used as a between-subject factor. Within-subjects factors included trial, training session, and outcome value. ANOVAs and post hoc paired and independent-samples $t$ tests were used (see Results for $p$ values). The Bonferroni correction was used for multiple comparisons within an experiment. Statistical tests were performed using SPSS version 25 (IBM).

\section{Results}

Expression profiles and effects of Neuropilin 2 on the corticostriatal pathway

We previously showed that the ligand Sema3F is expressed in the postnatal cortex, while the receptor Nrp2 is uniquely localized to the apical dendrites of cortical neurons in vitro (Tran et al., 2009). First, we asked whether this specific localization of Nrp2 in apical dendrites could be recapitulated in vivo in layer $\mathrm{V}$ pyramidal neurons that are known to project to striatal neurons. We used a previously validated anti-Nrp2 antibody (Tran et al., 2013) and demonstrated that Nrp2 is localized in layer $\mathrm{V}$ cortical neuron soma and apical dendrites from adult (6-9 months old) WT mice, but not in $N r p 2$ global $\mathrm{KO}$ mice (Fig. $1 A-D$ ). Interestingly, very little or no Nrp2 is detected in basal dendrites, which is also consistent with our previous in vitro findings. Further, we performed a triple immunofluorescent staining using antiDARPP32 (Ouimet et al., 1984), anti-Nrp2, and anti-VGLUT1 antibodies to detect the presence of Nrp2 in several VGLUT1 ${ }^{+}$ corticostriatal terminals in close apposition to DARPP $32^{+}$processes in the striatum of WT adult brain sections but not in Nrp2null brain sections (Fig. 1E, merged panels and insets). This suggests that Nrp2 is present at the level of corticostriatal presynaptic axon terminals, where it may play a role in the development of axospinous corticostriatal synapses and the maintenance of synaptic activity in SPNs.

Next, using double-immunofluorescent staining with antiNrp2 and anti-DARPP-32, we detected colocalization of Nrp2 and DARPP32 within the same SPNs as early as postnatal day 3 (P3) through P14 and P21, and also in adult (6-9 months) SPNs (Fig. $1 F)$. Nrp2 expression in SPNs seems to be present in both the somata and the dendritic processes (Fig. $1 F$ ).

\section{Modifications in intrinsic electrophysiological properties of SPNs in Nrp2 $2^{-/-}$mutant mice}

Next, we investigated whether the loss of Nrp2 signaling affects the intrinsic electrophysiological properties of SPNs. We tested responses to injected current pulses in SPNs recorded in wholecell current clamp from WT and $\mathrm{Nrp}^{-1-}$ animals. We found a significant increase in the depolarization to current injection at higher current steps in $\mathrm{Nrp} 2^{-1-}$ mice compared with WT controls (Fig. 2A-C). Also, spike frequency in response to depolarizing somatic current injection was significantly increased in SPNs from $\mathrm{Nrp} 2^{-1-}$ mice compared with WT controls (Fig. 2D). Consistent with an increased intrinsic excitability of SPNs in $\mathrm{Nrp} 2^{-1-}$ mice, the rheobase current was significantly lower in the KO mice compared with WT SPNs. $(366.41 \pm 13.93$ vs $315.69 \pm 18.39$ for WT and $N r p 2^{-1-}$, respectively; Fig. $2 E, F ; p=0.011$, unpaired $t$ test, 13-20 neurons/animal/genotype, averaged from $n=4$ animals/genotype). Analysis of the action potential waveform revealed no significant differences between the WT and Nrp2 $2^{-1-}$ mice (data not shown).

\section{Adult spiny projection neurons from $\mathrm{Nrp} 2^{-1-}$ mice have normal dendritic arborization, but exhibit supernumerary spines}

Our previous findings in layer $\mathrm{V}$ pyramidal neurons in the cortex showed that Nrp2 plays a role to restrain spine number (Tran et al., 2009). Here, we examined whether Nrp2 has a similar effect in SPNs by measuring spine density in biocytin-filled SPNs (Fig. $3 A-D$ ) following whole-cell recordings in $\mathrm{Nrp} 2^{-1-}$ and control mice. We found on average a $\sim 23 \%$ increase in spine density on dendrites between 50 and $100 \mu \mathrm{m}$ away from the cell soma in 
A

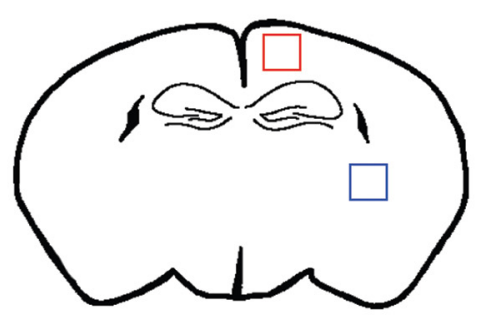

\section{Cortex}
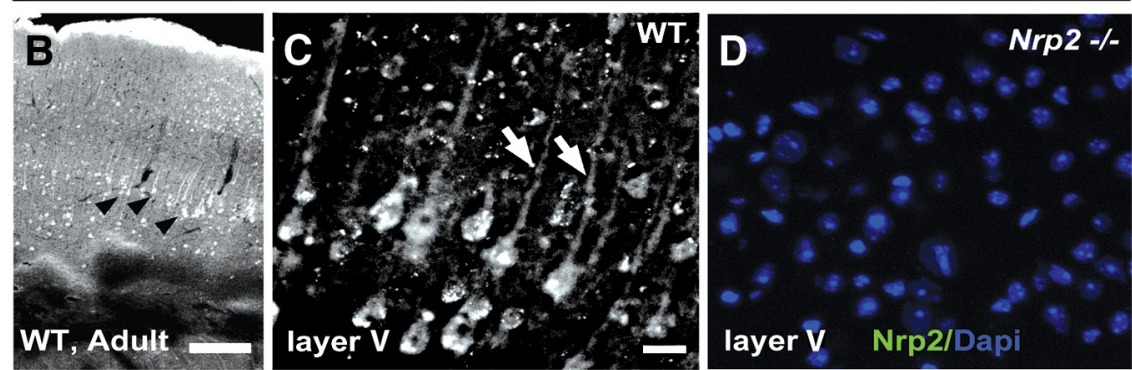

Striatum

$\mathbf{E}$
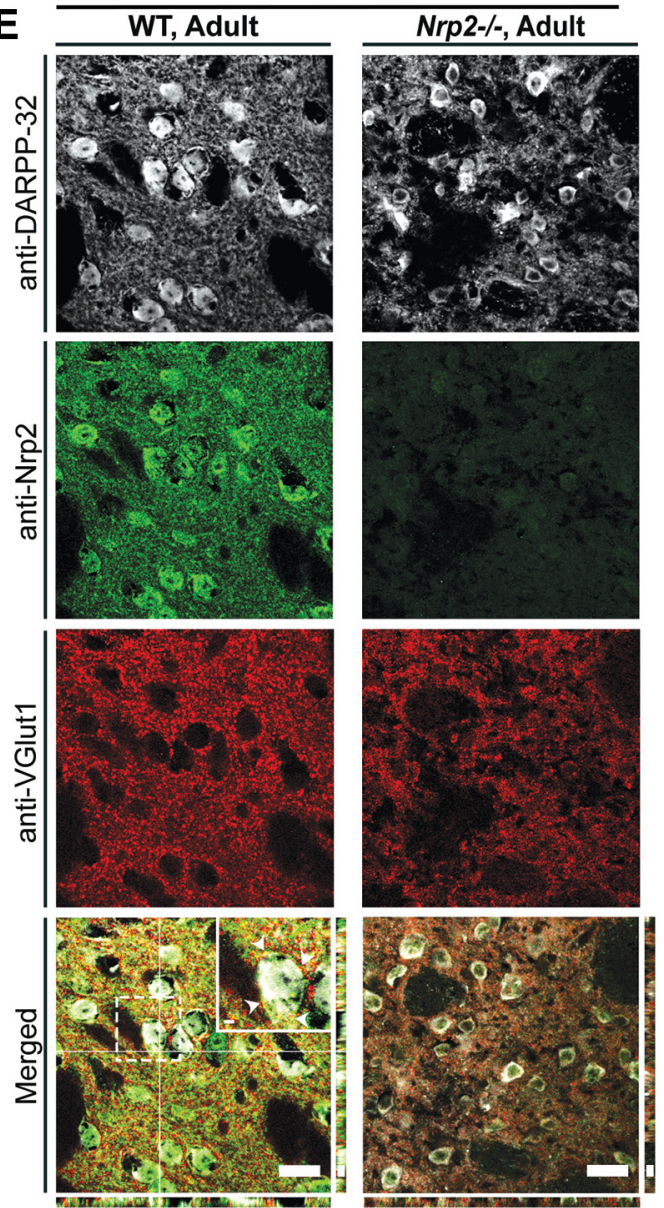

WT, Striatum
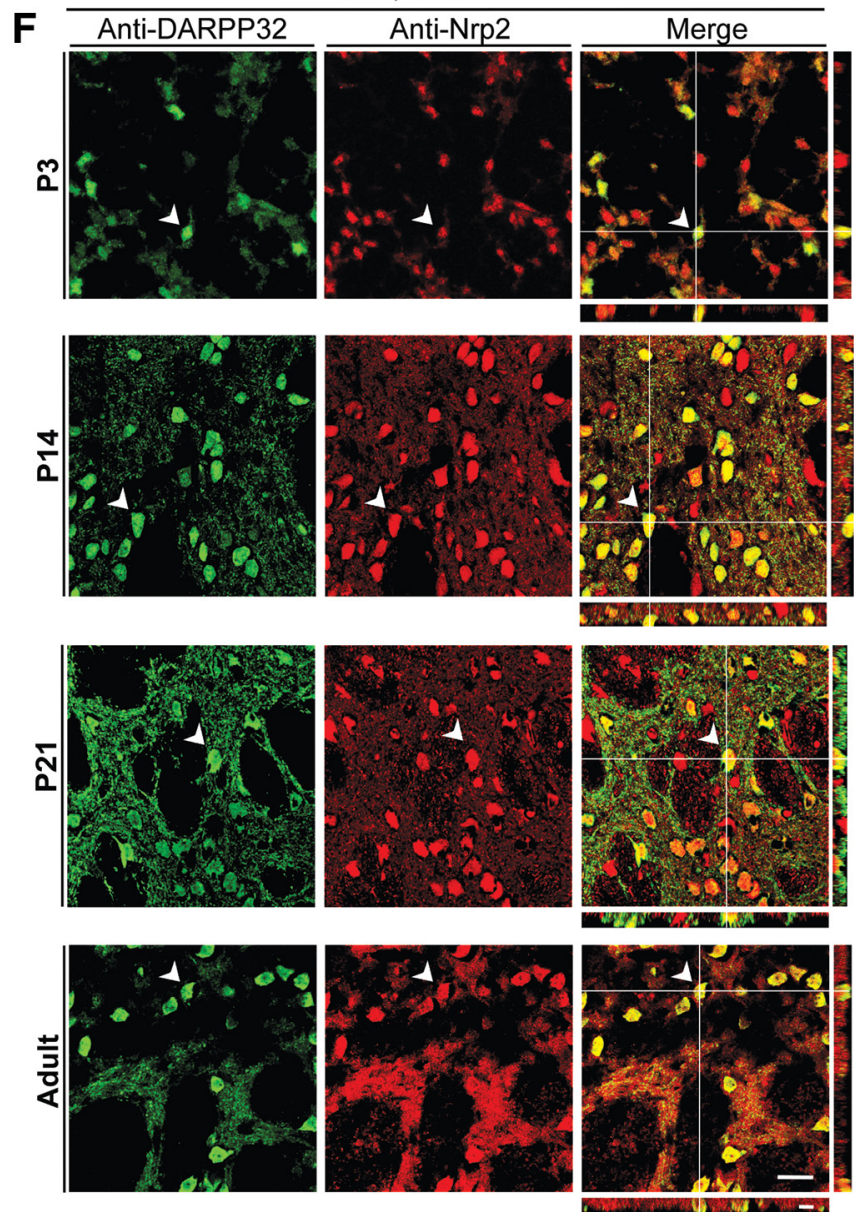

Figure 1. Nrp2 protein is expressed in cortical neurons and striatal SPNs. A, Schematic of a coronal brain section where representative confocal images were obtained from imaging the cortex (red box) and striatum (blue box). B, Expression of Nrp2 is detected in cortical neurons (black arrowheads), mainly in layer V, and sparsely in layers II/III and VI. C, High magnification of layer V cortical neurons reveals Nrp2 localization in pyramidal neuron soma and apical dendrites (white arrows). D, No expression is observed in adult Nrp2 ${ }^{-\prime-}$ cortical neurons. $\boldsymbol{E}$, Adult WT (left column) and Nrp2 ${ }^{-/-}$(right column) sections triple labeled with anti-Nrp2, anti-VGLUT1, and anti-Darpp-32. Nrp2 expression is detected in VGLUT1 ${ }^{+}$terminals (in merged panel, white arrowheads, boxed inset). $\boldsymbol{F}$, WT P3, P14, P21, and adult brain sections coimmunolabeled with anti-Nrp2 (red) and anti-Darpp-32 (green). SPNs coexpressing Nrp2 and Darpp-32 (white arrowheads). Scale bars: $\boldsymbol{B}, 200$ $\mu \mathrm{m} ;$ (in C) C, $\boldsymbol{D}, 50 \mu \mathrm{m} ; \boldsymbol{E}, 20 \mu \mathrm{m} ; \boldsymbol{E}, z$-plane, $8 \mu \mathrm{m} ; \boldsymbol{F}, 20 \mu \mathrm{m} ; \boldsymbol{F}, z$-plane, $8 \mu \mathrm{m}$.

Nrp2 $2^{-1-}$ compared with WT SPNs (Fig. $3 E ; 68.63 \pm 4.17$ vs $89.18 \pm 6.87$ for WT and $N r p 2^{-1-}$ respectively; unpaired $t$ test $\left.t_{(6)}=5.116, p=0.0022\right)$. We analyzed the dendritic arborization of four biocytin-filled SPNs each from Nrp2 $2^{-1-}$ and WT mice with Neurolucida (Fig. $3 F, G$ ). Sholl analysis revealed no difference in the number of primary dendrites (WT: $5.5 \pm 0.5$ vs $N r p 2^{-l-}: 6.5 \pm 1.04 ; t=0.87, p=0.42$, unpaired $t$ test), total dendritic length (WT, $2668 \pm 281 \mu \mathrm{m} ; N r p 2^{-1-}, 3004 \pm 253 ; t=$ $0.89 ; p=0.41$; unpaired $t$ test), dendritic branching number $\left(\mathrm{WT}, 6.75 \pm 1.25 ; \mathrm{Nrp}^{-/-}, 5.75 \pm 0.48 ; t=0.75, p=0.48\right.$, unpaired $t$ test), or number of Sholl intersections (WT, $170.8 \pm$ $23.34 ; N r p 2^{-I-}, 192.3 \pm 17.72 ; t=0.73, p=0.49$, unpaired $t$ test; Fig. $3 H-K)$.

$\mathrm{Nrp} 2^{-/-}$mice exhibit impaired paired-pulse facilitation from cortical-stimulated input to the striatum

Next, we asked whether loss of Nrp2 altered cortical excitatory input to SPNs. To address this, we stimulated corticostriatal inputs while recording striatal SPNs in $N r p 2^{-1-}$ and WT adult mice (Fig. $4 A, B$ ). Short-term plasticity was tested by using dou- 
ble pulse stimulation with a range of different interstimulus intervals (ISIs; 20, $40,60,120$, and $200 \mathrm{~ms}$ ), and we calculated the paired-pulse ratio (PPR). As previously described, corticostriatal synapses measured in WT SPNs exhibit paired-pulse facilitation, indicating a low-release probability (Ding et al., 2008). Here, the PPR was significantly reduced in SPNs from $N r p 2^{-1-}$ neurons compared with WT $\left(\mathrm{PPR}_{20 \mathrm{msWT}}=1.764 \pm\right.$ 0.11 vs $\mathrm{PPR}_{20 \mathrm{msCKO}}=1.19 \pm 0.08, p=$ $0.0009 ; \mathrm{PPR}_{40 \mathrm{msWT}}=1.69 \pm 0.13 \mathrm{vs}$ $\mathrm{PPR}_{40 \mathrm{msCKO}}=1.11 \pm 0.07, p=0.001$; $\mathrm{PPR}_{60 \mathrm{msWT}}=1.61 \pm 0.13 \mathrm{vs} \mathrm{PPR}_{60 \mathrm{msCKO}}=$ $0.99 \pm 0.05, p=0.0002 ; \mathrm{PPR}_{80 \mathrm{msWT}}=$ $1.47 \pm 0.12$ vs $\mathrm{PPR}_{80 \mathrm{msCKO}}=1.06 \pm 0.09$, $p=0.01 ; \mathrm{PPR}_{100 \mathrm{msWT}}=1.36 \pm 0.10 \mathrm{vs}$ $\mathrm{PPR}_{100 \mathrm{msCKO}}=1.05 \pm 0.09, p=0.03$; $\mathrm{PPR}_{120 \mathrm{msWT}}=1.36 \pm 0.13 \mathrm{vs} \mathrm{PPR}_{120 \mathrm{msCKO}}$ $=0.98 \pm 0.04, p=0.007 ; \mathrm{PPR}_{200 \mathrm{msWT}}=$ $1.21 \pm 0.07$ vs $\mathrm{PPR}_{200 \mathrm{msCKO}}=0.97 \pm 0.07$, $p=0.03 ; n=14-22$ SPNs per condition; Fig. 4C-F). Grouped analysis also reveals significant differences between the Nrp2 $2^{-/-}$ mice and their littermate controls for corticostriatal short-term plasticity (Fig. 4G; $F_{(1,213)}=62.41, p=0.0001$, two-way ANOVA; $F_{(5,30)}=7.67, p<0.0001$; genotype: $F_{(1,26)}=10.19, p=0.0037$; interaction: $F_{(5,130)}=2.4, p=0.0406$. Post hoc analysis Sidak multiple-comparison test: WT vs KO: $20 \mathrm{~ms}, p=0.0037 ; 40 \mathrm{~ms}$, 0.0149; $60 \mathrm{~ms}, 0.0011 ; 80 \mathrm{~ms}, 0.0499 ; 100$ $\mathrm{ms}, 0.166$; $200 \mathrm{~ms}, 0.335$; Fig. $4 G$ ). Altogether, these observations indicate that the loss of Nrp2 significantly increases the initial release probability from corticostriatal synapses.

\section{$N r p 2^{-/-}$mice are impaired in goal-}

directed instrumental behavior

Based on the observed structural and physiological alterations in cortical and striatal neurons in $N r p 2^{-1-}$ mice, we examined performance in an operant task known to depend on the corticostriatal pathway (Shiflett and Balleine, 2011; Hart et al., 2014). We trained mice to make lever press responses to obtain food pellets. All mice learned the task, and response rates increased over the course of training, as shown by a significant main effect of training session on response rate (repeated-measures ANOVA: $F_{(9,144)}$ $=13.97, p=0.0001$; Fig. $5 A$ ). Overall, $N r p 2^{-1-}$ mice responded at a significantly lower rate compared with WT mice, as shown by a main effect of genotype on response rate (ANOVA: $F_{(1,16)}=$ $5.50, p=0.036)$. Furthermore, $N r p 2^{-1-}$ and WT mice differed in the rate of acquisition of the task. By the 10th training session, WT mice responded at a significantly greater rate compared with $N r p 2^{-1-}$ mice, but no significant difference was observed on sessions 1-9 (Fig. 5B).

We next examined goal-directed behavior in $\mathrm{Nrp}^{-1-}$ mice. Goal-directed behavior is evident when animals flexibly alter their actions in response to changes in outcome value (Adams and Dickinson, 1981). This behavioral flexibility is dependent on corticostriatal pathway plasticity (Shiflett et al., 2010; Shan et al.,
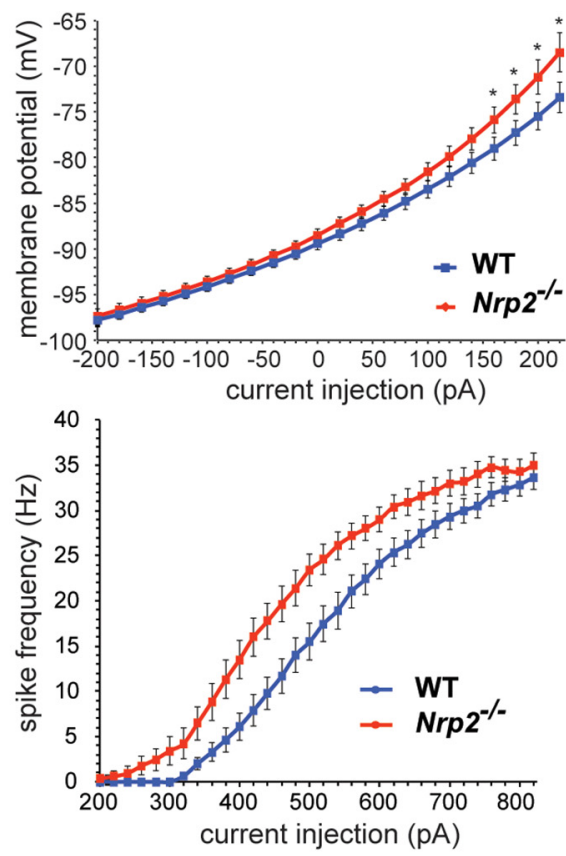

$\mathbf{F}_{2}$

$\mathbf{F}_{1}$
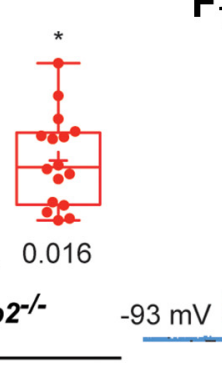

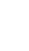

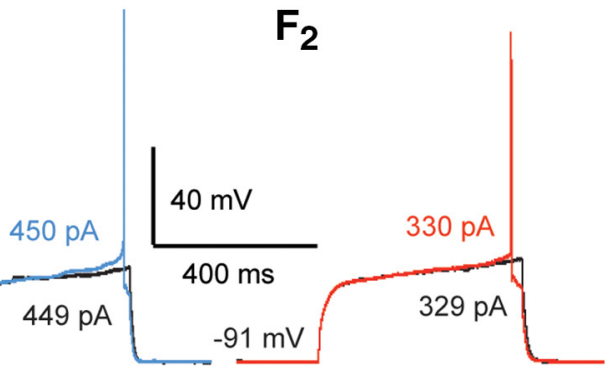

Figure 2. Changes in SPN intrinsic properties and spine density in Nrp2 $2^{-/-}$mice. $\boldsymbol{A}, \boldsymbol{B}$, Membrane voltage responses to injected current pulses of an SPN recorded in WT $(\boldsymbol{A})$ and $N r p 2^{-/-}(\boldsymbol{B})$ mice. Note that similar current injection elicits higher firing frequency in Nrp2 $2^{-/-}$mice ( $\boldsymbol{B}$, red) than in WT mice $(\boldsymbol{A}$, blue). $\boldsymbol{C}$, Current-voltage curves of SPNs recorded in WT (blue) and (red) mice. $D$, Graph representing the spike frequency in response to injected current pulses in WT (blue) and Nrp2 (red) mice. $\boldsymbol{F}$, Representative current-clamp traces showing the rheobase current of an SPN recorded in WT $(\boldsymbol{F 1})$ and $N r p 2^{-/-}$mice $(\boldsymbol{F 2})$. Note that the rheobase current is lower in F2 (Nrp2 $\left.{ }^{-/-}\right)$than in F1 (WT).

2014; Hawes et al., 2015). To test goal-directed behavior, we used a selective-satiety procedure to reduce the value of the instrumental outcome and then probed the responses of animals in an extinction paradigm. This test occurred after animals had acquired an instrumental response. Feeding WT mice the pellets used during instrumental training significantly reduced their subsequent responding during the extinction test, compared with responses they made after being fed an alternative flavor of pellets (paired $t$ test, $t_{(10)}=2.27, p=0.046$; Fig. $5 C$ ). In contrast, $\mathrm{Nrp} 2^{-1-}$ mice responded at similar rates during the extinction tests, whether following feeding on the instrumental outcome or an alternative flavor of pellets (Fig. 5C). Overall, we observed a significant outcome value $\times$ genotype interaction (ANOVA: $\left.F_{(1,16)}=4.95, p=0.041\right)$ on response rates during the devaluation tests. The lack of sensitivity to changes in outcome value in $\mathrm{Nrp2} 2^{-1-}$ mice was not a consequence of differences in food consumption. We found no difference between genotypes on the number of food pellets consumed during the satiety procedure (data not shown). This suggests that the inability to adjust responding following changes in the desirability of an outcome likely reflects impaired acquisition or control of goal-directed behavior. 

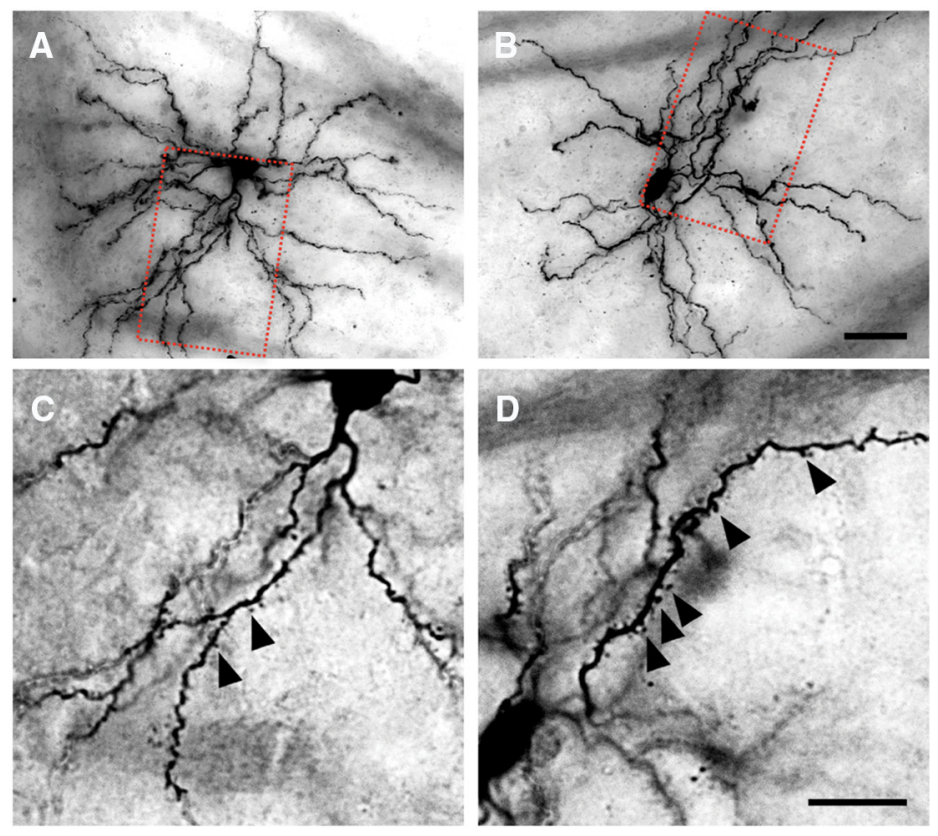

E
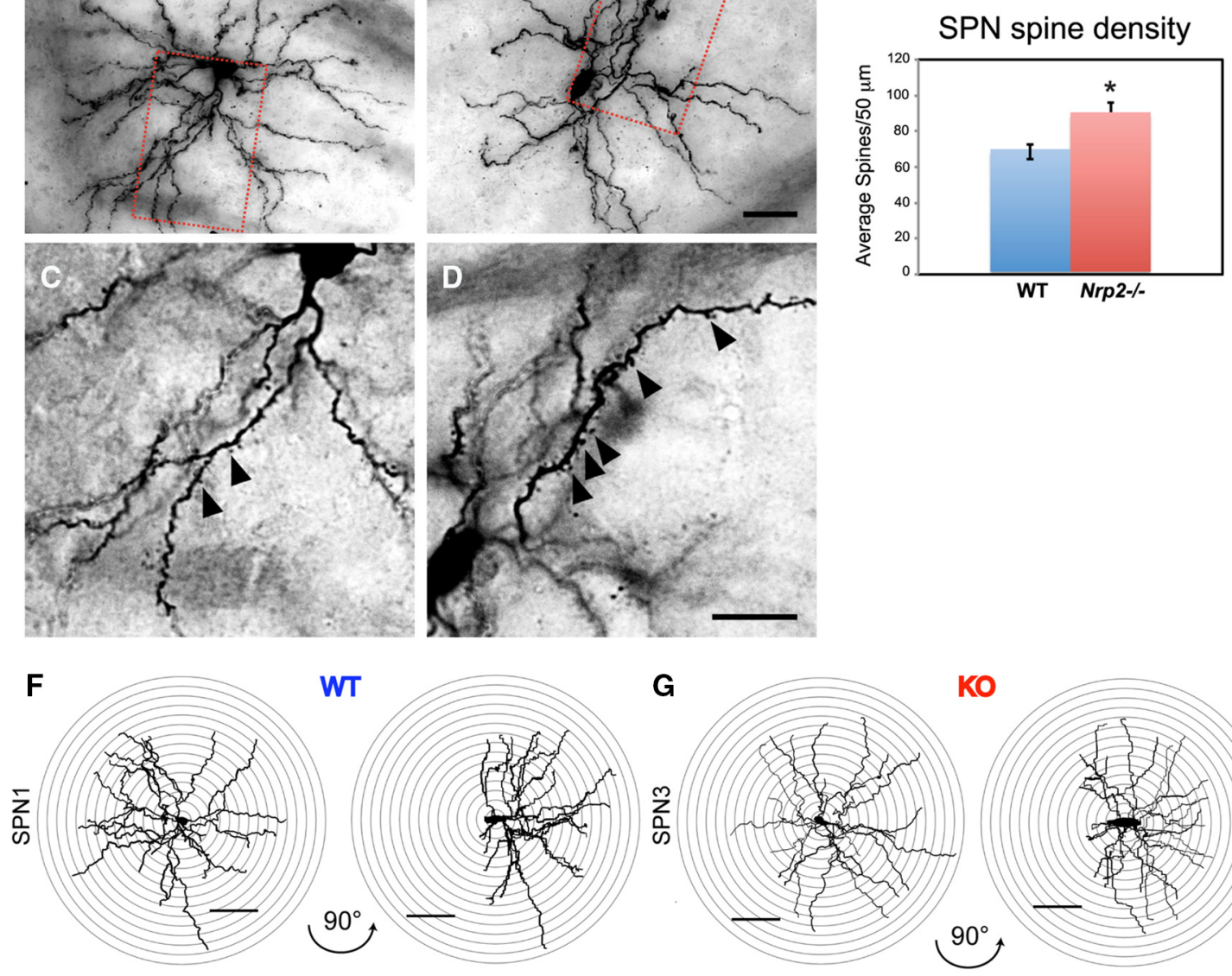

KO
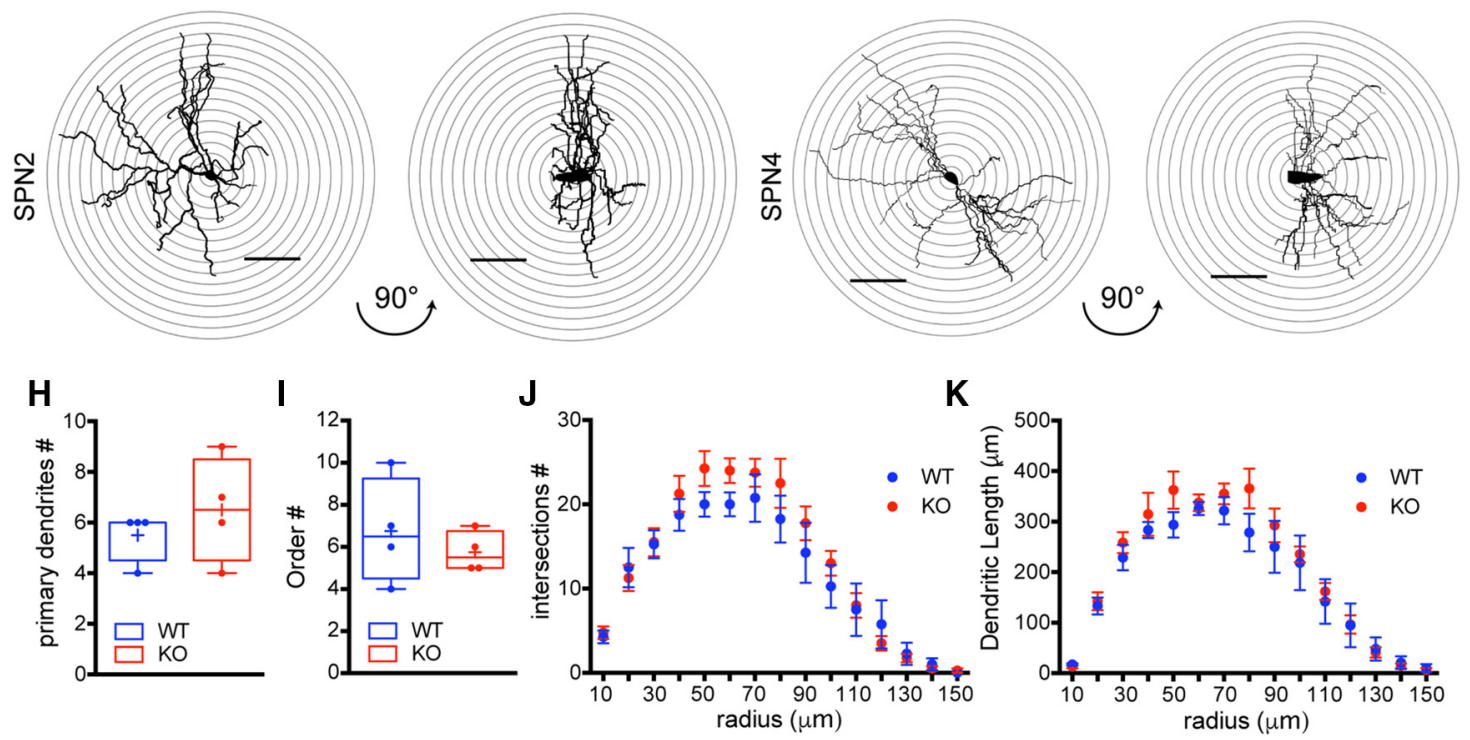

Figure 3. Nrp2 $2^{-/-}$SPNs display supernumerary spines, but normal dendritic arborization. $A, B$, Representative images taken from a WT and Nrp2 ${ }^{-/-}$SPN back-filled with biocytin. $2 \mathrm{D}$ confocal images are reconstructed from complete $z$-stacks. $\boldsymbol{C}, \boldsymbol{D}$, Single-plane images of WT and $N r p 2^{-1-}$ SPNs were taken at higher magnification within the area indicated by the red-dashed boxes in $\boldsymbol{A}$ and $\boldsymbol{B}$, respectively. $\boldsymbol{E}$, Quantification of the average number of spines per $50 \mu \mathrm{m}$ from reconstructed $z$-stack images of $2 \mathrm{D}$ neurons. Error bars are the mean $\pm S D$; unpaired $t$ test, ${ }^{*} p=0.0022 . S$ Cale bars: $\boldsymbol{A}($ for $\boldsymbol{A}, \boldsymbol{B}), \boldsymbol{C}($ for $\boldsymbol{C}, \boldsymbol{D}), 20 \mu \mathrm{m} . \boldsymbol{F}, \mathbf{G}, 3 \mathrm{D}$ reconstruction of the dendritic arborization of two SPNs recorded and biocytin filled in WT (F; SPN1, SPN2) and Nrp2 ${ }^{-/-}$mice (G; SPN3, SPN4). Left panels correspond to $x-y$ view, and right panels are rotated $90^{\circ}$ around the $y$-axis. Scale bars, $50 \mu \mathrm{m} . \boldsymbol{H}, \boldsymbol{I}$, Box plot representing the number of primary dendrites $(\boldsymbol{H})$ and the order number of dendritic branching $(\boldsymbol{I})$ of $3 \mathrm{D}$ reconstructed SPNs. $\boldsymbol{J}, \boldsymbol{K}$, Graphs representing the number of intersections $(\boldsymbol{E})$ and the dendritic length $(\boldsymbol{F})$ of $3 \mathrm{D}$ reconstructed SPNs. Sholl analysis revealed no effect of genotype on dendritic arborization. WT (blue) and Nrp2 ${ }^{-/-}$(red) mice; error bars are the mean \pm SEM, unpaired $t$ test. $\boldsymbol{H}, \boldsymbol{I}, p=0.419$ and $p=0.483$, respectively; $J, K, p=0.413$ and $p=0.495$, respectively. 
A

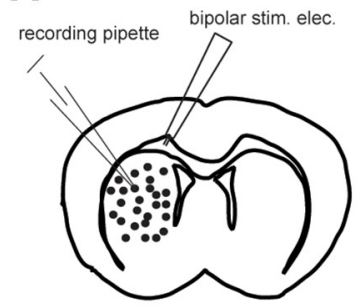

B

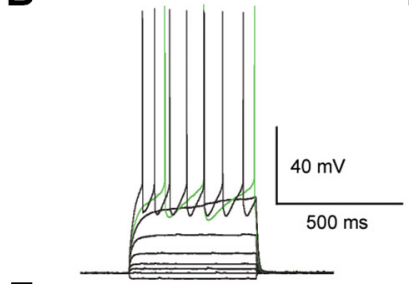

$F_{1}$

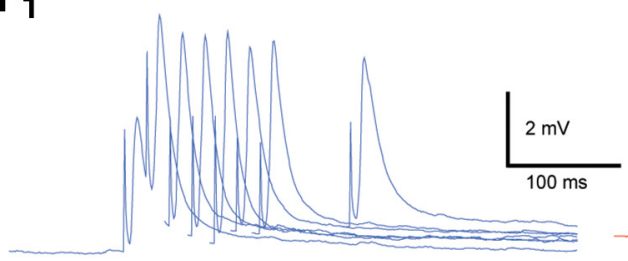

$20 \mathrm{~ms}$

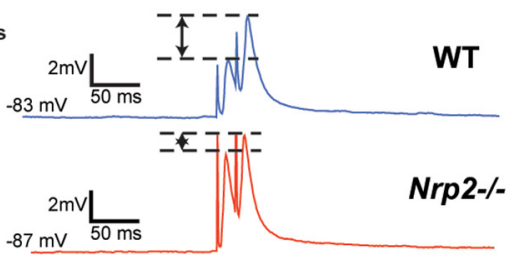

D

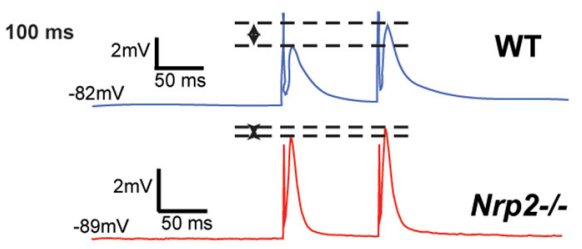

$F_{2}$

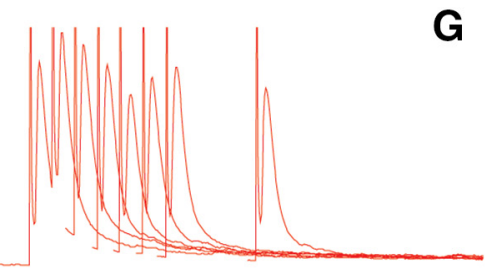

E
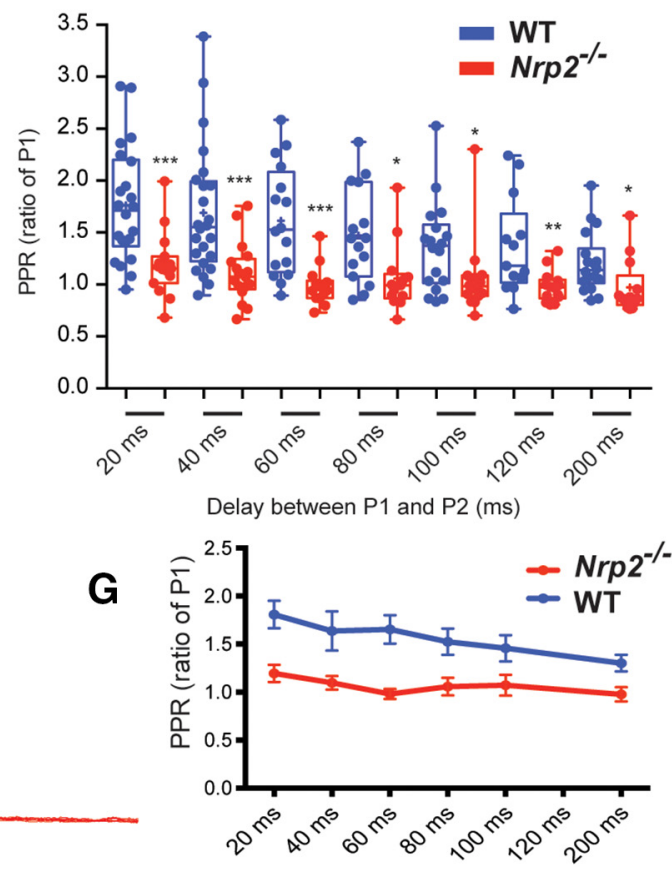

Figure 4. Defects in corticostriatal short-term plasticity onto SPNs in Nrp2 $2^{-\prime-}$ mice. $A$, Schematic illustrating the experimental paradigm where SPNs were recorded in coronal striatal slices. A bipolar stimulating electrode was placed in the corpus callosum to stimulate corticostriatal fibers. $\boldsymbol{B}$, Example of voltage responses to current steps for injection of an SPN. C, $\boldsymbol{D}$, Representative examples of EPSPs measured in SPNs after a pair of electrical stimuli. ISIs: $20 \mathrm{~ms}$ in $\boldsymbol{C} ; 100 \mathrm{~ms}$ in $\boldsymbol{D}$. Responses of SPNs recorded in WT are represented in blue, and mutant in red. Note that in WT SPNs, there is a strong paired-pulse facilitation that is impaired in $\mathrm{Nrp2}^{-\prime-}$. $\boldsymbol{E}$, Box plots representing the paired-pulse ratio of the responses at different ISIs (20, $40,60,80,100,120$, and $200 \mathrm{~ms}$ ) for the two genotypes. Responses are expressed as a ratio of the response to the first stimulus. $\boldsymbol{F}$, Representative current-clamp traces showing corticostriatal EPSPs elicited by paired stimuli with increasing ISIs in WT mice $(\boldsymbol{F} 1)$ and Nrp2 ${ }^{-/-}(\boldsymbol{F} 2)$. G, Summary graph of PPRs recorded from medium spiny neurons plotted against ISIs for cortical stimulation in WT (blue) and $\mathrm{Nrp2}^{-\prime-}$ (red). Box plots represent the minimum, maximum interquartile range, the mean, and the median. Statistical analysis was made using unpaired $t$ test $(\boldsymbol{E})$ where ${ }^{* * *} p=0.0009,20 \mathrm{~ms} ;{ }^{* * *} p=0.0010,40 \mathrm{~ms} ;{ }^{* * *} p=0.0002,60 \mathrm{~ms} ;{ }^{*} p=0.0117,80 \mathrm{~ms} ;{ }^{*} p=0.0391,100 \mathrm{~ms} ;{ }^{* *} p=0.0071,120 \mathrm{~ms}$; and ${ }^{*} p=0.0303,200 \mathrm{~ms}$ comparison between WT and Nrp2 ${ }^{-/-}$, and two-way ANOVA (G).

\section{Acute deletion of Nrp2 in adult layer $\mathrm{V}$ cortical neurons increased apical dendritic spine number}

We addressed the question of whether the different alterations measured in the global $\mathrm{Nrp}^{-/-} \mathrm{KO}$ animals could be attributed to Nrp2 expression in cortical layer $\mathrm{V}$ neurons or striatal neurons (Fig. 1). We used the conditional floxed $N r p 2$ mouse line (Walz et al., 2002) crossed with the Cre recombinase-ERT2 driver line under the regulation of the Etv1 promoter, which was previously demonstrated to be expressed specifically in layer V cortical neurons (Harris et al., 2014; Fig. $6 A, B)$. The Nrp2 CKO cassette contains a tauGFP-pA ${ }^{+}$insert that will be expressed under the $\mathrm{Nrp} 2$ promoter upon successful Cre recombination. After generating the Nrp2f/f;Etv1-CreERT2 animals and treating them with tamoxifen at 4-6 months of age, we confirmed specific deletion of Nrp2 in layer V cortical neurons by performing immunofluorescent staining with anti-GFP primary antibodies on Nrp2f/f;Etv1 ${ }^{+/+}$(control) or Nrp2fff; Etv1 ${ }^{+} /$Cre (CKO) mouse brain sections.
A
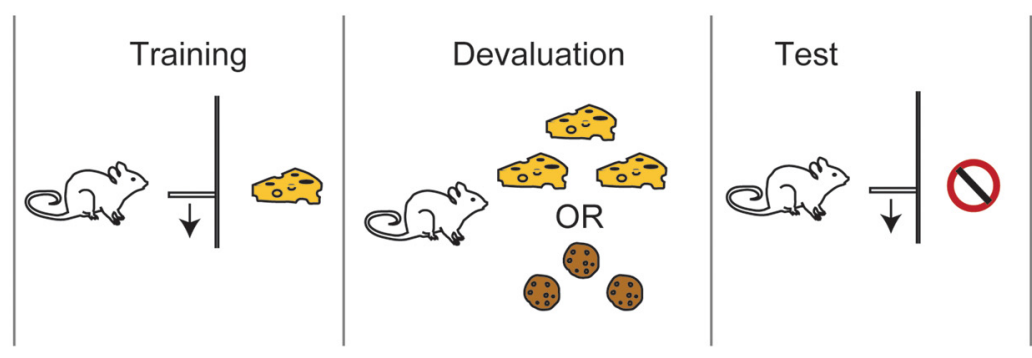

B
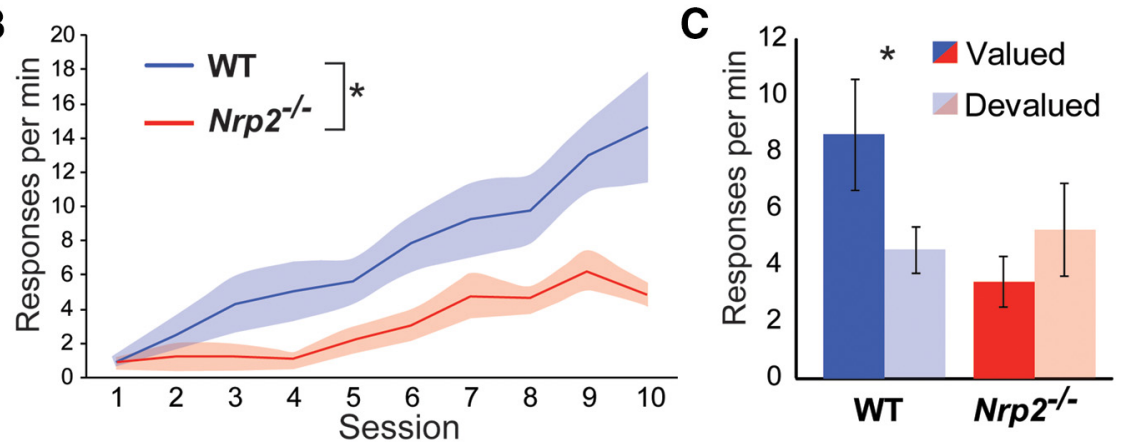

Figure 5. Nrp2 $2^{-1-}$ mice are impaired in goal-directed instrumental action. $\boldsymbol{A}$, We trained $\mathrm{Nrp2} 2^{-/-}$and WT mice on an instrumental learning task with a selective satiety procedure to devalue the instrumental outcome or an alternative outcome. $\boldsymbol{B}$, All mice acquired an instrumental response that increased in rate with training; however, the rate of acquisition was reduced in Nrp2 ${ }^{-1-}$ mice. C, When the instrumental outcome was devalued, WT mice significantly reduced their responding compared with when an alternative food was devalued. In contrast, $\mathrm{Nrp2} 2^{-1-}$ mice responded at similar rates following both devaluation sessions. Paired $t$ test, ${ }^{*} p=0.046$; error bars indicate \pm 1 SEM. 
A
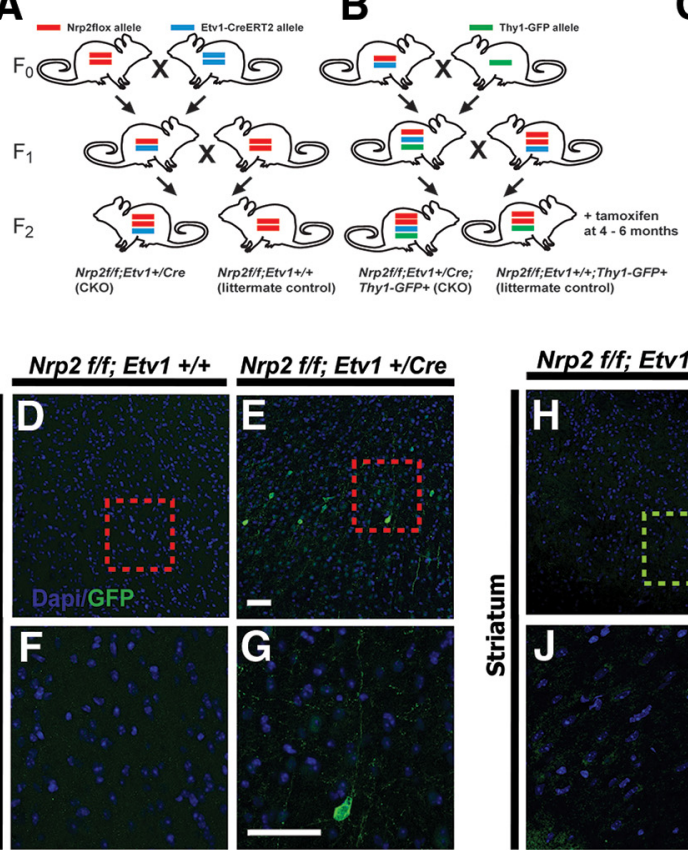
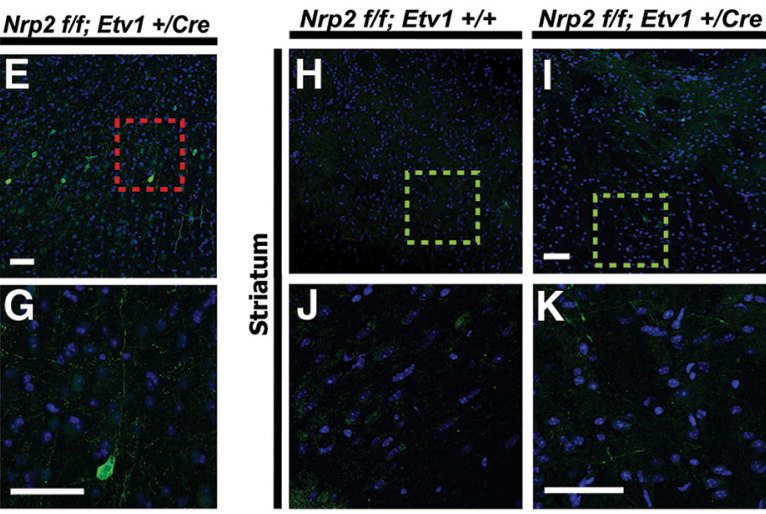

C
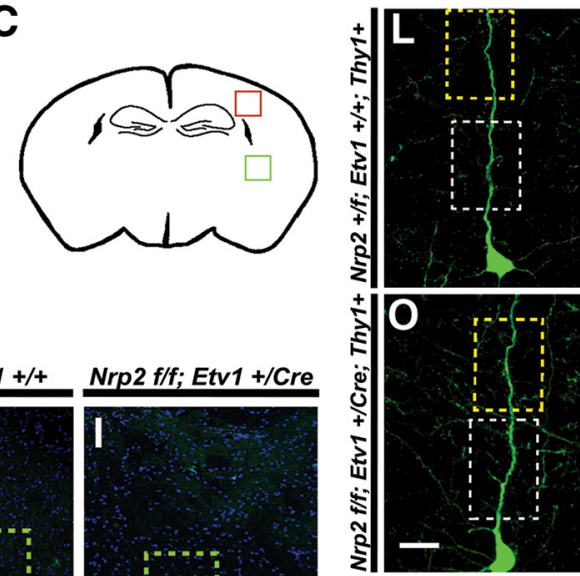

R
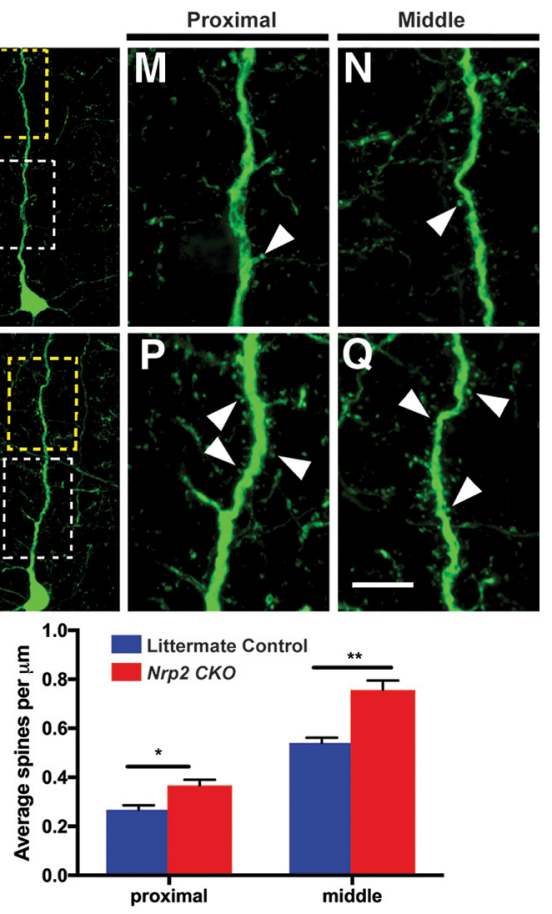

Figure 6. Specific deletion of Nrp2 in adult layer V pyramidal neurons leads to increased dendritic spine numbers in vivo. $\boldsymbol{A}$, Nrp2flox mice $\left(\mathrm{F}_{0}\right)$ were $\mathrm{crossed}$ with Etv1-CreERT2 $\left(\mathrm{F}_{0}\right)$ mice to generate heterozygous $\left(\mathrm{F}_{1}\right)$ mice, and the $\mathrm{F}_{1}$ mice were backcrossed with Nrp2flox mice to generate homozygous floxed Nrp2flox mice with or without Etv1-Cre ${ }^{+}$alleles $\left(\mathrm{F}_{2}\right)$. $\boldsymbol{B}$, $\mathrm{F}_{1}$ progeny developed in $\boldsymbol{A}$ were

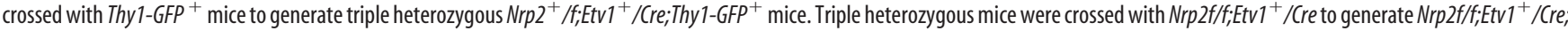
Thy 1-GFP ${ }^{+}$and littermate controls $\left(\mathrm{F}_{2}\right)$. All $\mathrm{F}_{2}$ in both $\boldsymbol{A}$ and $\boldsymbol{B}$ were treated twice on consecutive days with tamoxifen at $4-6$ months. $\boldsymbol{C}-\boldsymbol{K}$, Schematic of a coronal adult brain section; red box indicates the cortical region of images in $\boldsymbol{D}-\boldsymbol{G}$ immuno-labeled with anti-GFP showing successful Cre recombination in layer $V$ neurons ( $\boldsymbol{E}$, red box enlarged in $\boldsymbol{G})$ but not in littermate control $(\boldsymbol{D}$, red box enlarged in $\boldsymbol{F}$ ); green box indicates striatal region of image in $\boldsymbol{H}-\boldsymbol{K}$; no GFP ${ }^{+}$striatal neurons were detected in $\boldsymbol{H}$ (green box enlarged in $\boldsymbol{J}$ ) or in I (green box enlarged in $\boldsymbol{K}$ ). Scale bars: $\boldsymbol{E}$ (for $\boldsymbol{D}$, $\boldsymbol{E}), \boldsymbol{I}($ for $\boldsymbol{H}, \boldsymbol{I}), \boldsymbol{G}($ for $\boldsymbol{F}, \boldsymbol{G}), \boldsymbol{K}($ for $\boldsymbol{J}, \boldsymbol{K}), 50 \mu \mathrm{m}$. $\boldsymbol{L}-\mathbf{N}$, Representative image of a neuron from a Nrp2+/f; Etv $1^{+/+}$; Thy 1 -GFP + adult mouse brain. $\mathbf{0}-\mathbf{Q}$, Representative image of a neuron from a Nrp2f/f;Etv $1^{+} /$Cre; Thy1-GFP ${ }^{+}$adult mouse brain. Yellow and white boxes outline middle regions, $45-90 \mu \mathrm{m}$ from the soma and proximal regions, and $0-45 \mu \mathrm{m}$ from the soma, respectively. White arrows show dendritic spines in proximal regions $\boldsymbol{M}$ and $\boldsymbol{P}$, enlarged from yellow box region in $\boldsymbol{L}$ and $\mathbf{O}$, respectively. White arrows show dendritic spines in middle regions $\boldsymbol{N}$ and $\mathbf{Q}$, enlarged from yellow box region in $\boldsymbol{L}$ and $\boldsymbol{O}$, respectively. $\boldsymbol{R}$, Quantification of spine density on layer $V$ apical dendrites in proximal and middle regions. A significantly higher number of spines are found on Nrp2f/f;Etv $1^{+} /$Cre; Thy1-GFP ${ }^{+}$neurons compared with littermate controls for both regions. Error bars are the mean \pm SEM; unpaired $t$ test; ${ }^{*} p=0.0157 ;{ }^{* *} p=0.0027$ compared with littermate controls. Scale bars: $\mathbf{O}$ (for $\boldsymbol{L}, \mathbf{0}), \mathbf{Q}($ for $\boldsymbol{M}, \boldsymbol{N}, \mathbf{P}, \mathbf{Q}), 15 \mu \mathrm{m}$.

We detected $\mathrm{GFP}^{+}$cortical pyramidal neurons with apical dendrites that extended to the pial surface in adult Nrp2f/f;Etv ${ }^{+} / \mathrm{Cre}$ CKO mice treated with tamoxifen but not in Nrp2f/f;Etv1 ${ }^{+/+}$ control littermates (Fig. 6C-G). Importantly, we found no expression of $\mathrm{GFP}^{+}$SPNs in Nrp2f/f;Etv1 ${ }^{+} /$Cre CKO or Nrp2f/f; $E t v 1^{+/+}$mouse control brains, further demonstrating the specificity of our acute Nrp2 deletion in adult layer $\mathrm{V}$ cortical neurons (Fig. 6C,H-K).

To determine whether Nrp2 in adult layer V neurons is required for the maintenance of apical dendritic spine number, as observed in the Nrp2-null mice, we crossed Nrp2f/f;Etv1 ${ }^{+} / \mathrm{Cre}$ and Nrp2f/f;Etv1 ${ }^{+/+}$mice with the Thy1-GFP M-reporter line, where GFP is expressed sparsely in layer $\mathrm{V}$ pyramidal neurons (Fig. $6 B, C$ ). We found that Nrp2f/f;Etv1 ${ }^{+} / C r e ; T h y 1-G F P^{+}$ (CKO) animals treated with tamoxifen at 4-6 months of age exhibited a significantly increased number of apical dendritic spines (Fig. $6 L-Q), \sim 1.4$-fold more in the proximal $(0-45 \mu \mathrm{m}$ from soma; $0.37 \pm 0.05$ spines $/ \mu \mathrm{m}$ in $\mathrm{CKO}$ vs $0.27 \pm 0.04$ spines $/ \mu \mathrm{m}$ in control mice; $t_{(6)}=3.334, p=0.0157$, unpaired $t$ test; Fig. $6 R)$ and $\sim 1.4$-fold more in the middle dendritic regions (45-90 $\mu \mathrm{m}$ from soma; $0.76 \pm 0.08$ spines $/ \mu \mathrm{m}$ in CKO vs $0.54 \pm 0.04$ spines $/ \mu \mathrm{m}$ in control mice; $t_{(6)}=4.901, p=$ 0.0027 , unpaired $t$ test; Fig. $6 R$ ). This finding suggests that Nrp2 plays a role in dendritic spine maintenance in adult layer $\mathrm{V}$ cortical neurons.
Loss of Nrp2 in adult cortical layer V projection neurons alters corticostriatal short-term plasticity but preserves intrinsic electrophysiological properties in SPNs

To address whether specific deletion of Nrp2 in adult layer $\mathrm{V}$ cortical neurons influences corticostriatal short-term plasticity and/or affects SPNs intrinsic physiological properties, we performed whole-cell recordings of SPNs in both Nrp2f/f;Etv $1^{+} / \mathrm{Cre}$ (Nrp2 CKO) and Nrp2f/f;Etv1 ${ }^{+/+}$(WT littermate control) brain slices from adult mice treated with tamoxifen at 4-6 months of age. In contrast with results obtained using $N r p 2^{-/-}$mice, SPNs recorded from $\mathrm{Nrp} 2 \mathrm{CKO}$ mice show no significant changes in intrinsic excitability compared with WT littermates. Indeed, we measured similar current-voltage responses (Fig. 7A-C; $n=16$ $\mathrm{WT} ; n=15 \mathrm{CKO}$ ), spike frequency (Fig. $7 D ; n=14 \mathrm{WT} ; n=14$ $\mathrm{CKO}$ ), input resistance (Fig. $7 E ; n=17 \mathrm{WT} ; n=15 \mathrm{CKO}$ ), resting membrane potential (Fig. $7 F ; n=17 \mathrm{WT} ; n=15 \mathrm{CKO}$ ) as well as in the rheobase current of SPNs (Fig. 7-I; $n=17 \mathrm{WT} ; n=$ $14 \mathrm{CKO})$. These results strongly suggest that the changes in intrinsic excitability of SPNs we observed in the full $\mathrm{Nrp}^{-1-}$ mice are due to Nrp2 expression in striatal SPNs themselves and not in deep-layer cortical neurons.

Next, we tested the short-term plasticity at corticostriatal synapses in the Nrp2 CKO mice compared with WT littermates. As above, we used electrical cortical stimulation with a range of dif- 


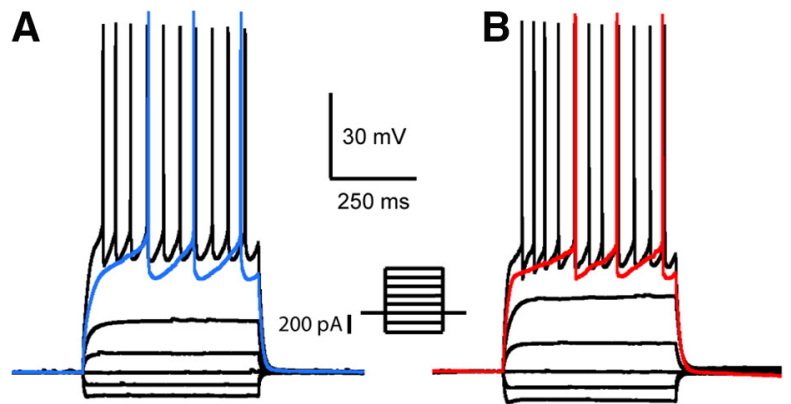

E

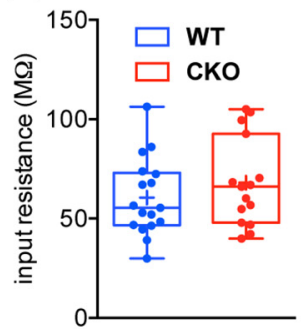

$\mathbf{F}$

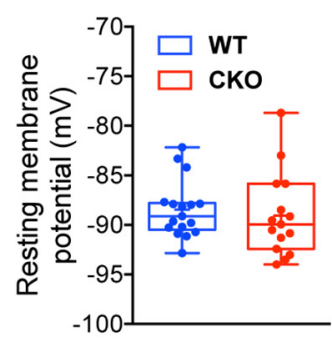

C

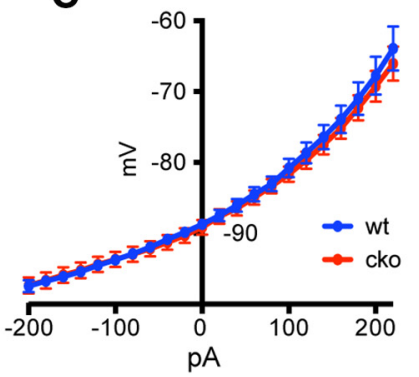

G

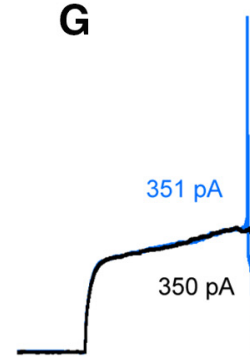

D

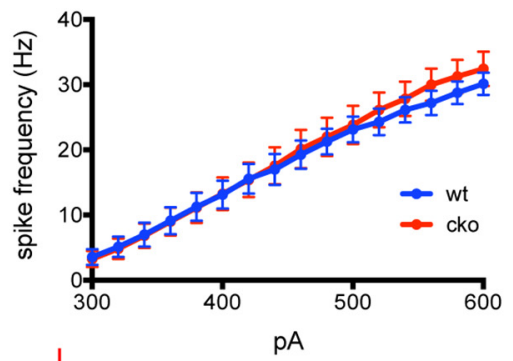

H
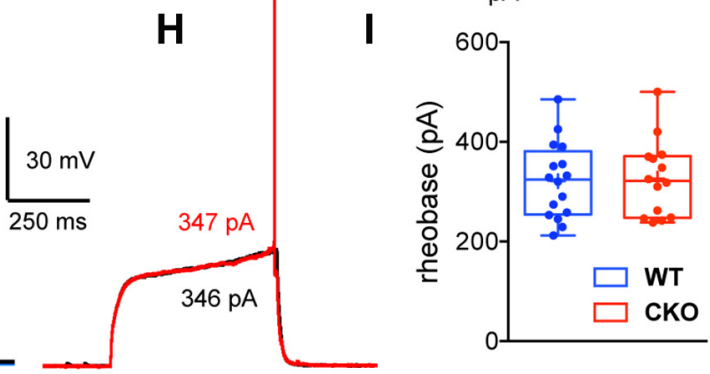

Figure 7. SPNs recorded in Nrp2 CKO mice have normal intrinsic properties. $\boldsymbol{A}, \boldsymbol{B}$, Membrane voltage responses to injected current pulses of a SPN recorded in a WT ( $\boldsymbol{A}$ ) and Nrp2 $\mathrm{CKO}$ (B) mice. C, Current-voltage curves of SPNs recorded in WT (blue line) and Nrp2 CKO mice (red line). D, Graph representing the spike frequency in response to injected current pulses in WT (blue line) and Nrp2 (K0 mice (red line). E, Box plots representing the input resistance measured at rest (WT: blue; Nrp2 CKO: red). $\boldsymbol{F}$, Box plots representing the resting membrane potential (WT: blue; Nrp2 CKO: red). $\mathbf{G}, \boldsymbol{H}$, Representative current-clamp traces showing the rheobase current of an SPN recorded in WT (G) and Nrp2 CKO (H) mice. I, Box plots representing rheobase current (WT: blue; Nrp2 CKO: red). Box plots represent the minimum, maximum interquartile range, the mean, and the median. Statistical analysis was performed using unpaired $t$ test $(\boldsymbol{F})$ and two-way ANOVA $(\boldsymbol{G})$.

A

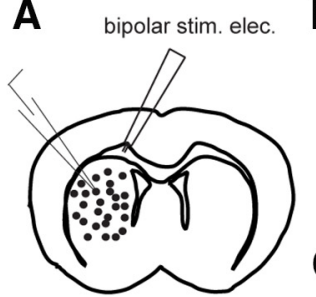

$B_{1}$

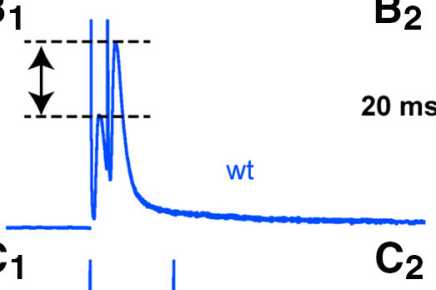

$\mathrm{B}_{2}$

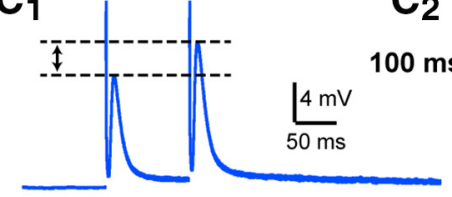

$\mathbf{F}$

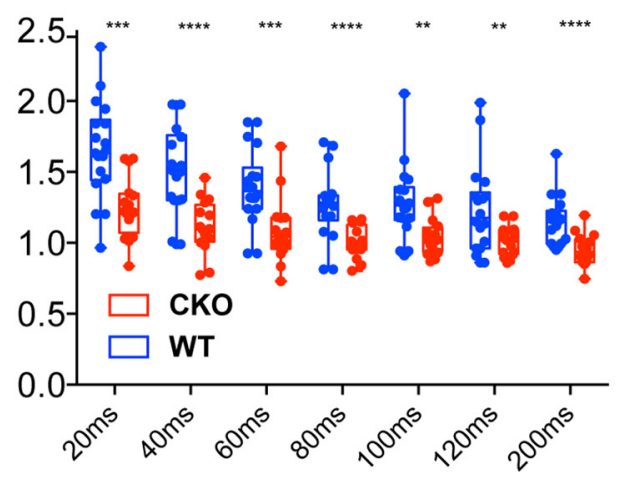

G
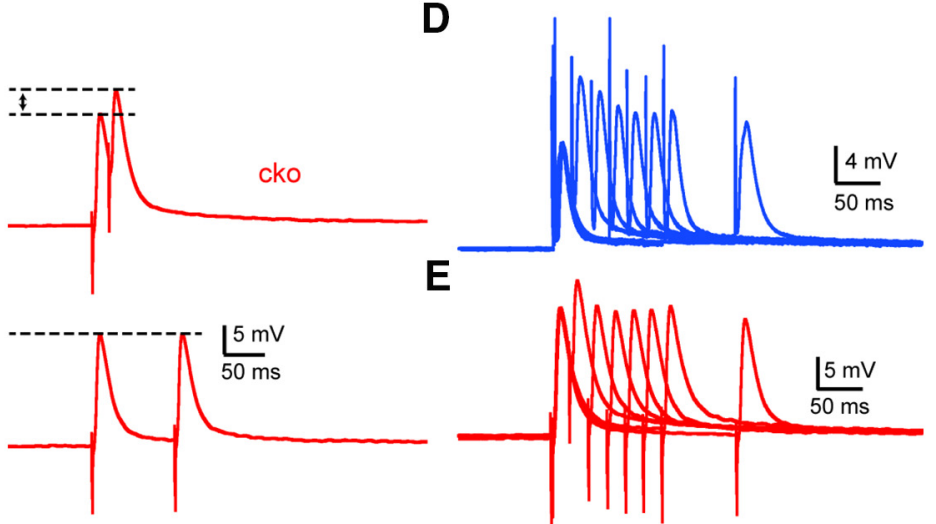

Figure 8. Altered corticostriatal short-term plasticity in Nrp2 CKO mice. A, Schematic illustrating the experimental paradigm where SPNs were recorded in coronal striatal slices. A bipolar stimulating electrode was placed in the corpus callosum to stimulate corticostriatal fibers. $\boldsymbol{B}, \boldsymbol{C}$, Representative examples of EPSPs measured in SPNs after a pair of electrical stimuli. ISIs: 20 ms in $\boldsymbol{K}$; $100 \mathrm{~ms}$ in $\boldsymbol{L}$ (K1, L1: WT; K2 and L2: Nrp2 CK0 mice). Note that in WT SPNs there is a strong paired-pulse facilitation that is impaired in Nrp2 CK0. D, E, Representative current-clamp traces showing corticostriatal EPSPs elicited by paired stimuli with increasing ISIs in WT $(\boldsymbol{M})$ and $\mathrm{Nrp2}$ CKO $(\boldsymbol{N})$ mice. $\boldsymbol{F}$, Box plots representing the paired-pulse ratio of the responses at different ISIs ( $20,40,60,80$, $100,120$, and $200 \mathrm{~ms})$ for the two genotypes and unpaired $t$ test was performed $\left({ }^{* * *} p=0.0003,20 \mathrm{~ms} ;{ }^{* * * *} p<0.0001,40 \mathrm{~ms} ;{ }^{* * *} p=0.0002,60 \mathrm{~ms} ;{ }^{* * * *} p<0.0001,80 \mathrm{~ms} ;{ }^{* *} p=0.0016\right.$, $100 \mathrm{~ms}^{* *} p=0.0043,120 \mathrm{~ms}^{* * * *} p<0.0001,200 \mathrm{~ms}$ comparison between WT and Nrp2 ${ }^{-/-}$). Responses are expressed as the amplitude of the second EPSP divided by the amplitude of the first one. G, Summary graph of PPRs recorded from medium spiny neurons plotted against ISIs for cortical stimulation in WT (blue) and Nrp2 CK0 (red). 
ferent ISIs $(20,40,60,120$, and $200 \mathrm{~ms})$. Here, similar to the results obtained in $\mathrm{Nrp}^{-1-}$ mice, we measured a strong alteration in the PPR at corticostriatal synapses in Nrp2 CKO (Fig. $8 J-P ; \mathrm{PPR}_{20 \mathrm{~ms} \mathrm{TT}}=1.674 \pm 0.091 \mathrm{vs} \mathrm{PPR}_{20 \mathrm{msCKO}}=1.248 \pm$ $0.0505, p=0.0003 ; \mathrm{PPR}_{40 \mathrm{msWT}}=1.516 \pm 0.072 \mathrm{vs} \mathrm{PPR}_{40 \mathrm{~ms} \mathrm{CKO}}$ $=1.124 \pm 0.044, p<0.0001 ; \mathrm{PPR}_{60 \mathrm{msWT}}=1.416 \pm 0.054 \mathrm{vs}$ $\mathrm{PPR}_{60 \mathrm{msCKO}}=1.091 \pm 0.0538, p=0.0002 ; \mathrm{PPR}_{80 \mathrm{~ms} W \mathrm{~T}}=$ $1.301 \pm 0.061$ vs $\mathrm{PPR}_{80 \mathrm{msCKO}}=1.01 \pm 0.026, p<0.0001$; $\mathrm{PPR}_{100 \mathrm{msWT}}=1.294 \pm 0.064 \mathrm{vs} \mathrm{PPR}_{100 \mathrm{msCKO}}=1.048 \pm 0.031$, $p=0.0016 ; \mathrm{PPR}_{120 \mathrm{msWT}}=1.268 \pm 0.078 \mathrm{vs} \mathrm{PPR}_{120 \mathrm{msCKO}}=$ $1.013 \pm 0.02627, p=0.0043 ; \mathrm{PPR}_{200 \mathrm{msWT}}=1.171 \pm 0.042 \mathrm{vs}$ $\mathrm{PPR}_{200 \mathrm{msCKO}}=0.949 \pm 0.0258, p<0.0001 ; n=15-18$ SPNs per condition per genotype). Grouped analysis also reveals significant differences between the littermate controls and $\mathrm{Nrp} 2 \mathrm{CKO}$ animals for corticostriatal short-term plasticity $\left(\right.$ Fig. $8 P ; F_{(1,32)}=$ $21.75 ; p<0.0001$, two-way ANOVA). Altogether, these results strongly support the hypothesis that acute deletion of Nrp2 specifically in layer $\mathrm{V}$ cortical neurons is sufficient to alter corticostriatal short-term plasticity, replicating the data obtained in the global $N r p 2^{-1-}$ mice.

\section{Loss of Nrp2 in adult deep layer cortical neurons selectively impairs sensorimotor learning}

Next, we asked whether acute deletion of Nrp2 in adult layer V cortical neurons affects motor learning, anxiety, and goaldirected behaviors. We tested adult male Nrp2 CKO and littermate control mice on the open field test, the elevated zero maze, the accelerating rotarod, and instrumental behavior. We found no differences between genotypes on locomotor behavior as measured by distance traveled in the open field test (Fig. 9A,B), nor any effect on time spent in the center zone of the open field, suggesting no effect on anxiety (Fig. 9B). We confirmed this result in the elevated zero maze test, which also showed no effect of genotype on time spent in the open arms (Fig. 9C).

We found that mice lacking Nrp2 in layer V cortical neurons were impaired on the accelerating rotarod, a sensorimotor learning task. We found an overall reduced latency to fall in $\mathrm{Nrp2} \mathrm{CKO}$ mice compared with controls (ANOVA, $F_{(1,17)}=16.25, p=$ 0.001; Fig. 9D). Post hoc comparisons with Bonferroni correction revealed significantly reduced latency to fall on trials $6-9$ compared with controls $(\operatorname{tr} 6, p=0.001 ; \operatorname{tr} 7, p=0.001 ; \operatorname{tr} 8, p=0.004$; $\operatorname{tr} 9 p=0.001)$. In contrast, we found no effect in these mice on instrumental goal-directed action. Nrp2 $\mathrm{CKO}$ and littermate control mice acquired an instrumental response and showed similar patterns of responding across training sessions (Fig. 9E). During the extinction test following devaluation, both groups of mice significantly reduced their responses when the instrumental outcome was devalued compared with when the outcome was valued. This devaluation effect was significant in control mice (paired $t$ test, $\left.t_{(13)}=3.46, p=0.004\right)$ and $N r p 2 C K O$ mice $\left(t_{(13)}=\right.$ $2.43, p=0.03)$. Unlike the global $N r p 2 \mathrm{KO}$, selective deletion of Nrp2 in adult layer $V$ cortical neurons did not affect goal-directed learning or action control.

\section{Discussion}

Our results demonstrate that Nrp2 signaling is required for the development and maintenance of cortical neuron spine density, corticostriatal transmission, and function in vivo (Fig. 10). We show that Nrp2 is present throughout the corticostriatal pathway. The loss of Nrp2 disrupts corticostriatal transmission, increases SPN excitability, and spine density, and impairs goaldirected behavior. Furthermore, we found that the deletion of Nrp2 selectively in layer $\mathrm{V}$ cortical neurons in adult animals in-
A

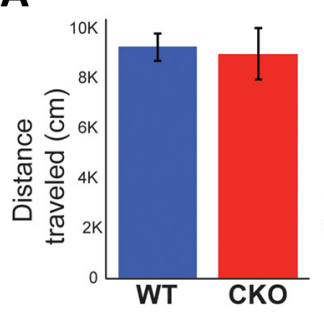

B
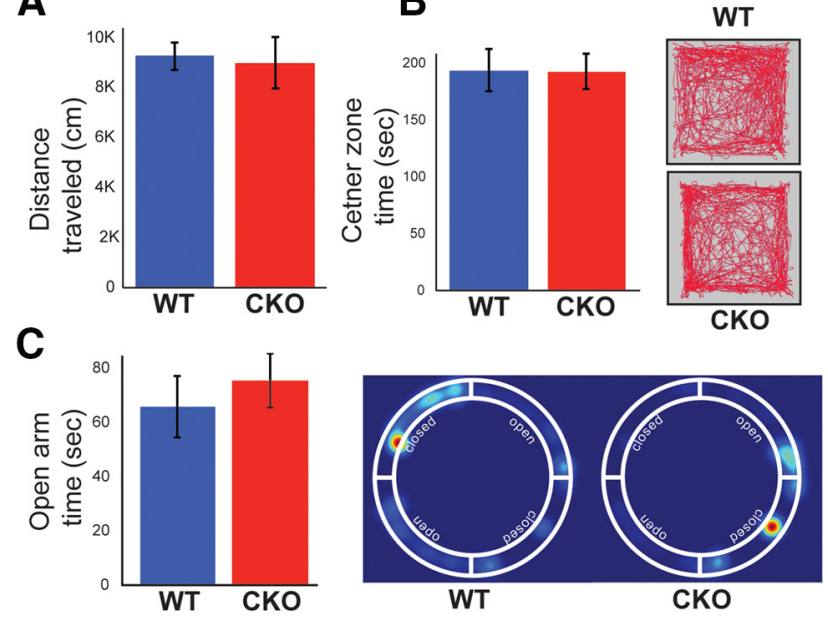

D

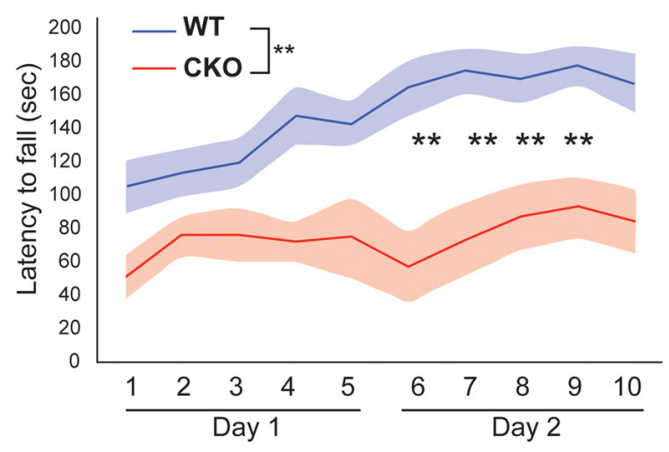

$\mathbf{E}$
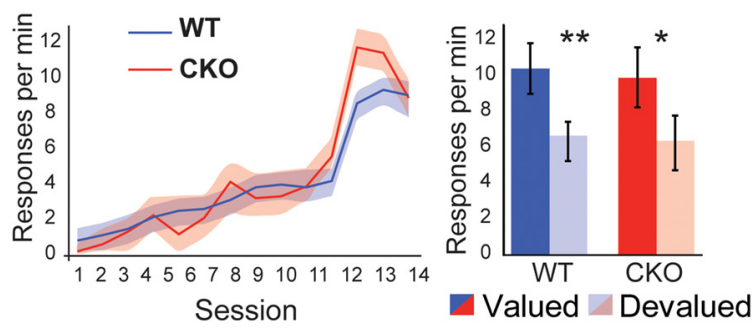

Figure 9. The effects of selective Nrp2 deletion in adult layer V cortical neurons on sensorimotor and instrumental learning. $A, B$, No significant difference was detected between WT and $\mathrm{Nrp2}$ CKO mice for distance or time spent in the center of the open field test. C, No significant difference between WT and Nrp2 CKO mice for time spent in the open arm of the elevated zero maze. $\boldsymbol{D}$, CKO mice showed a significant impairment in rotarod performance. Their overall latency to fall was significantly reduced, and post hoc comparisons revealed significantly reduced latency on trials 6-9. E, CKO and control mice did not differ on acquisition of an instrumental response and performance across sessions with increasing response requirements. Following devaluation of the instrumental outcome, both groups of mice showed a significant reduction in response rate compared with when the outcome is still valued. ${ }^{*} p=0.004 ;{ }^{* *} p=$ 0.001 . Error bars represent \pm 1 SEM.

creased spine density in apical dendrites of those neurons, altered corticostriatal plasticity, and impaired motor skill learning. Overall, our study uncovers novel and essential roles for Nrp2 signaling in adult corticostriatal synaptic transmission and associated behaviors.

Nrp2 is expressed throughout the corticostriatal pathway and regulates dendritic spine frequency

Multiple areas of cerebral cortex, including sensory, motor, and association regions, project to the striatum (Kemp and Powell, 1970; Jones et al., 1977; Veening et al., 1980; Royce, 1982; Goldman-Rakic and Selemon, 1986; Reiner et al., 2010; Hin- 
tiryan et al., 2016; Shipp, 2017). This provides the basal ganglia with the sensory and motor planning information needed to execute its role in motor control. The corticostriatal pathway mostly originates in layer $\mathrm{V}$ (and to a lesser extent in layer III; Jones et al., 1977; Wilson, 1987; Gerfen, 1989; Cowan and Wilson, 1994; Levesque et al., 1996; Reiner et al., 2003, 2010; Parent and Parent, 2006), and virtually all corticostriatal axons synapse on dendritic spines of SPNs. Here, we show for the first time that Nrp2 is also expressed in some presynaptic VGLUT1 ${ }^{+}$ corticostriatal axon terminals and in striatal SPNs at young postnatal ages and in adult mice. While previously we showed that Sema3F and its receptor Nrp2 act as negative regulators of spine development and synapse formation (Tran et al., 2009), it remained unclear whether Nrp2 also affects dendritic arborization. However, our Sholl analysis results clearly indicate that Nrp2 does not play a role in SPN dendritic arborization, but instead we found a significant increase in spine number on SPN dendrites of $\mathrm{Nrp2}^{-/-}$compared with control mice. Furthermore, results from the conditional Nrp2 knockout demonstrated that $\mathrm{Nrp} 2$ is required in adult layer $\mathrm{V}$ cortical neurons to maintain their proper spine number and distribution. Indeed, our results are consistent with the role of $\mathrm{Nrp} 2$ in regulating spine frequency and distribution not only during postnatal, but also in the adult animal. When this spine maintenance mechanism is dysregulated may contribute to some of the abnormal corticostriatal physiology observed in the $\mathrm{Nrp}^{-1-}$ mutants. It has been shown that spine density and distribution are critical for proper functional synaptic transmission, integration, and plasticity (Elston and DeFelipe, 2002; Nimchinsky et al., 2002; Ballesteros-Yáñez et al., 2006; Alvarez and Sabatini, 2007). Interestingly, a recent study shows that Sema3F-Nrp2/PlxnA3 signaling involves the association with GluA1 to mediate homeostatic scaling in cortical neurons (Wang et al., 2017). Sema3F is prominently expressed in the striatum during development (Marín et al., 2001; Andrews et al., 2017). However, whether Sema3F is still expressed in the adult striatum to signal with Nrp2 for the recruitment of GluA1 to corticostriatal synapses is unclear. Future experiments are needed to address the mechanism of Sema3FNrp2 signaling in corticostriatal plasticity and function.

\section{Nrp2 signaling mediates short-term facilitation of corticostriatal synapses and SPN excitability}

Nrp2 is expressed in corticostriatal axon terminals, which puts it in a position to modify presynaptic release mechanisms. Indeed, a similar role in presynaptic homeostatic plasticity has been described for Semaphorin 2b-Plexin B signaling (Orr et al., 2017). Consistently, the loss of Nrp2 altered corticostriatal transmission, affecting neurotransmitter release probability and shortterm facilitation, which has been suggested to be important for the establishment and maintenance of membrane potential upstates in SPNs (Wilson, 1993; Kasanetz et al., 2006; Ding et al., 2008). Alternatively, the altered short-term facilitation we observed may be attributed to the increase in excitability in cortical neurons caused by loss of Nrp2 as it has been demonstrated that changes in excitability can influence synaptic transmission (Shu et al., 2006; Christie and Jahr, 2008; Ludwar et al., 2009; Zbili et al., 2016). These two mechanisms are not mutually exclusive.

We also found that SPNs recorded ex vivo in adult $\mathrm{Nrp}^{-1-}$ mice exhibited a significant increase in excitability. These electrophysiological modifications in SPNs in $\mathrm{Nrp}^{-1-}$ mice may influence spike integration, downstate-to-upstate transitions, and the induction of synaptic plasticity (Wilson, 1995; Nisenbaum et al., 1996; Hernandez-Lopez et al., 2000; Shen et al., 2004). These changes in the excitability of SPNs could be attributed to the loss of Sema3F-Nrp2 signaling within the striatum or they could be a consequence of upstream changes in layer $\mathrm{V}$ cortical activity and corticostriatal synapses. We addressed this question by acute deletion of Nrp2 specifically from cortical layer $\mathrm{V}$ neurons using $\mathrm{Nrpf/f}$ :Etv $1^{+} / \mathrm{Cre} \mathrm{CKO}$ mice treated with tamoxifen at adult age. In the Nrp2 CKO mice, we found alterations to corticostriatal plasticity like those observed in $\mathrm{Nrp} 2^{-1-}$ mice, confirming that these changes in PPR are a presynaptic mechanism (Jackman and Regehr, 2017) involving the layer V cortical neurons. These results are also consistent with the expression of $\mathrm{Nrp} 2$ in corticostriatal axons and with a role for Nrp2 in synaptic release of glutamate at corticostriatal synapses onto SPNs. Also, we demonstrated that in Nrp2 CKO mice, the intrinsic excitability of SPNs is not modified. These results suggest that expression of Nrp2 in SPNs is essential to maintain the proper excitability of these cells.

\section{Nrp2 signaling influences motor learning and goal-}

\section{directed action}

We previously reported that $\mathrm{Nrp}^{-/-}$mice are impaired in the accelerating rotarod, a motor learning task (Shiflett et al., 2015). Interestingly, acute deletion of Nrp2 specifically in layer $\mathrm{V}$ cortical neurons is sufficient to impair rotarod behavior. Our result is consistent with previous findings demonstrating that motor skill learning critically depends on basal glutamate release and associated synaptic plasticity from corticostriatal terminals (Floyer-Lea and Matthews, 2005; Yin et al., 2009; Kupferschmidt et al., 2019). We further demonstrate that $N r p 2^{-1-}$ mice are impaired on an instrumental task. $\mathrm{Nrp}^{-{ }^{-1}}$ mice showed reduced response rates during training, suggesting they have impairment in learning. 
However, response rates during instrumental acquisition do not predict an animal's choice strategy following devaluation. It is possible that $\mathrm{Nrp}_{2} 2^{-/-}$mice and controls learned similarly, and the deficit in $N r p 2^{-/-}$following devaluation reflects an impairment in decision-making.

Loss of goal-directed control occurs following lesions to the dorsomedial striatum or its afferent input from the medial prefrontal cortex (Ostlund and Balleine, 2005; Yin et al., 2005; Balleine et al., 2009). Both of these structures are affected by loss of Nrp2. Synaptic plasticity within the dorsomedial striatum is necessary for goal-directed learning (Shiflett et al., 2010; Shan et al., 2014; Hawes et al., 2015) and likely underlies changes in activity patterns across the striatum as animals learn (Yin et al., 2009; Thorn et al., 2010; Gremel and Costa, 2013; Hawes et al., 2015). Loss of Nrp2 may prevent goal-directed learning by interfering with corticostriatal synaptic plasticity or by affecting SPN intrinsic excitability. Plasticity of intrinsic excitability in striatal neurons accompanies goal-directed learning (Daoudal and Debanne, 2003; Hawes et al., 2015). Therefore, the enhanced SPN intrinsic excitability we observed in $\mathrm{Nrp}^{-1-}$ mice may interfere with the intrinsic excitability changes necessary for learning.

While Nrp2 CKO mice showed deficits in the motor skill learning, these mice showed intact performance in the instrumental goal-directed learning task, contrasting with the results obtained in $\mathrm{Nrp}^{-1-}$ mice. One possible explanation for this difference is that motor and goal-directed learning differ in their rate of acquisition and may therefore rely on different forms of corticostriatal plasticity. During motor learning, animals make trial-by-trial adjustments to motor patterns, and these learningrelated adjustments may depend on short-term corticostriatal synaptic plasticity of the type that is disrupted in the Nrp2 CKO mice (Kupferschmidt et al., 2019). Goal-directed learning, in contrast, does not rely on trial-by-trial adjustment and may use a different set of synaptic-plasticity mechanisms that may be spared in CKO mice. Another possibility is that the acute deletion of Nrp2 in adulthood may not be sufficient to disrupt goaldirected learning, whereas Nrp2 deletion in layer V cortical neurons from a developmental stage may be necessary.

Overall, our findings provide novel insights to better understand neurodevelopmental disease mechanisms, many of which are accompanied by an increase in dendritic spine number and/or aberrant organization of synaptic connectivity (Comery et al., 1997; Ramakers, 2002; Barros et al., 2009; Hayashi-Takagi et al., 2010; Hutsler and Zhang, 2010; Carlson et al., 2011; Penzes et al., 2011; Durand et al., 2012; Kim et al., 2013). Alterations in the morphology and physiology of neurons comprising the corticostriatal pathway are found across many disorders, including autism spectrum disorder, schizophrenia, fragile $\mathrm{X}$ syndrome, and mental retardation (Hayrapetyan et al., 2014; Portmann et al., 2014; Morris et al., 2015; Schubert et al., 2015). Understanding how factors that contribute to the development and function of the corticostriatal pathway, such as we illustrate here with Nrp2, may ultimately lead to better treatments for these disorders.

\section{References}

Adams CD, Dickinson A (1981) Instrumental responding following reinforcer devaluation. Q J Exp Psychol 33:109-121.

Alvarez VA, Sabatini BL (2007) Anatomical and physiological plasticity of dendritic spines. Annu Rev Neurosci 30:79-97.

Andrews WD, Barber M, Nemitz M, Memi F, Parnavelas JG (2017) Semaphorin3A-neuropilin1 signaling is involved in the generation of cortical interneurons. Brain Struct Funct 222:2217-2233.

Assous M, Kaminer J, Shah F, Garg A, Koos T, Tepper JM (2017) Differential processing of thalamic information via distinct striatal interneuron circuits. Nat Commun 8:15860.

Assous M, Faust TW, Assini R, Shah F, Sidibe Y, Tepper JM (2018) Identification and characterization of a novel spontaneously active bursty GABAergic interneuron in the mouse striatum. J Neurosci 38:5688-5699.

Balleine BW, O'Doherty JP (2010) Human and rodent homologies in action control: corticostriatal determinants of goal-directed and habitual action. Neuropsychopharmacology 35:48-69.

Balleine BW, Liljeholm M, Ostlund SB (2009) The integrative function of the basal ganglia in instrumental conditioning. Behav Brain Res 199:43-52.

Ballesteros-Yáñez I, Benavides-Piccione R, Elston GN, Yuste R, DeFelipe J (2006) Density and morphology of dendritic spines in mouse neocortex. Neuroscience 138:403-409.

Barros CS, Calabrese B, Chamero P, Roberts AJ, Korzus E, Lloyd K, Stowers L, Mayford M, Halpain S, Müller U (2009) Impaired maturation of dendritic spines without disorganization of cortical cell layers in mice lacking NRG1/ErbB signaling in the central nervous system. Proc Natl Acad Sci U S A 106:4507-4512.

Buchwald NA, Price DD, Vernon L, Hull CD (1973) Caudate intracellular response to thalamic and cortical inputs. Exp Neurol 38:311-323.

Carlson BR, Lloyd KE, Kruszewski A, Kim IH, Rodriguiz RM, Heindel C, Faytell M, Dudek SM, Wetsel WC, Soderling SH (2011) WRP/srGAP3 facilitates the initiation of spine development by an inverse F-BAR domain, and its loss impairs long-term memory. J Neurosci 31:2447-2460.

Cheng Y, Quinn JF, Weiss LA (2013) An eQTL mapping approach reveals that rare variants in the SEMA5A regulatory network impact autism risk. Hum Mol Genet 22:2960-2972.

Christie JM, Jahr CE (2008) Dendritic NMDA receptors activate axonal calcium channels. Neuron 60:298-307.

Comery TA, Harris JB, Willems PJ, Oostra BA, Irwin SA, Weiler IJ, Greenough WT (1997) Abnormal dendritic spines in fragile X knockout mice: maturation and pruning deficits. Proc Natl Acad Sci U S A 94:54015404.

Costa RM (2007) Plastic corticostriatal circuits for action learning. Ann N Y Acad Sci 1104:172-191.

Costa RM, Cohen D, Nicolelis MA (2004) Differential corticostriatal plasticity during fast and slow motor skill learning in mice. Curr Biol 14: $1124-1134$.

Cowan RL, Wilson CJ (1994) Spontaneous firing patterns and axonal projections of single corticostriatal neurons in the rat medial agranular cortex. J Neurophysiol 71:17-32.

Daoudal G, Debanne D (2003) Long-term plasticity of intrinsic excitability: learning rules and mechanisms. Learn Mem 10:456-465.

Demyanenko GP, Mohan V, Zhang X, Brennaman LH, Dharbal KE, Tran TS, Manis PB, Maness PF (2014) Neural cell adhesion molecule NrCAM regulates semaphorin $3 \mathrm{~F}$-induced dendritic spine remodeling. J Neurosci 34:11274-11287.

Ding JB, Oh WJ, Sabatini BL, Gu C (2011) Semaphorin 3E-plexin-D1 signaling controls pathway-specific synapse formation in the striatum. Nat Neurosci 15:215-223.

Ding J, Peterson JD, Surmeier DJ (2008) Corticostriatal and thalamostriatal synapses have distinctive properties. J Neurosci 28:6483-6492.

Durand CM, Perroy J, Loll F, Perrais D, Fagni L, Bourgeron T, Montcouquiol M, Sans N (2012) SHANK3 mutations identified in autism lead to modification of dendritic spine morphology via an actin-dependent mechanism. Mol Psychiatry 17:71-84.

Elston GN, DeFelipe J (2002) Spine distribution in cortical pyramidal cells: a common organizational principle across species. Prog Brain Res 136: 109-133.

Feng G, Mellor RH, Bernstein, M. Keller-Peck C, Nguyen QT, Wallace M, Nerbonne JM, Lichtman JW, Sanes JR (2000) Imaging neuronal subsets in transgenic mice expressing multiple spectral variants of GFP. Neuron 28:41-51.

Floyer-Lea A, Matthews PM (2005) Distinguishable brain activation networks for short- and long-term motor skill learning. J Neurophysiol 94: 512-518.

Fujii T, Uchiyama H, Yamamoto N, Hori H, Tatsumi M, Ishikawa M, Arima K, Higuchi T, Kunugi H (2011) Possible association of the semaphorin 3D gene (SEMA3D) with schizophrenia. J Psychiatr Res 45:47-53.

Gerfen CR (1989) The neostriatal mosaic: striatal patch-matrix organization is related to cortical lamination. Science 246:385-388. 
Gerfen CR, Surmeier DJ (2011) Modulation of striatal projection systems by dopamine. Annu Rev Neurosci 34:441-466.

Giger RJ, Cloutier JF, Sahay A, Prinjha RK, Levengood DV, Moore SE, Pickering S, Simmons D, Rastan S, Walsh FS, Kolodkin AL, Ginty DD, Geppert M (2000) Neuropilin-2 is required in vivo for selective axon guidance responses to secreted semaphorins. Neuron 25:29-41.

Goldman-Rakic PS, Selemon LD (1986) Topography of corticostriatal projections in nonhuman primates and implications for functional parcellation of the neostriatum. In: Sensory-motor areas and aspects of cortical connectivity (Jones EG, Peters A, eds), pp 447-466. New York: Plenum.

Greig LC, Woodworth MB, Galazo MJ, Padmanabhan H, Macklis JD (2013) Molecular logic of neocortical projection neuron specification, development and diversity. Nat Rev Neurosci 14:755-769.

Gremel CM, Costa RM (2013) Orbitofrontal and striatal circuits dynamically encode the shift between goal-directed and habitual actions. Nat Commun 4:2264.

Harris JA, Hirokawa KE, Sorensen SA, Gu H, Mills M, Ng LL, Bohn P, Mortrud M, Ouellette B, Kidney J, Smith KA, Dang C, Sunkin S, Bernard A, Oh SW, Madisen L, Zeng H (2014) Anatomical characterization of cre driver mice for neural circuit mapping and manipulation. Front Neural Circuits 8:76.

Hart G, Leung BK, Balleine BW (2014) Dorsal and ventral streams: the distinct role of striatal subregions in the acquisition and performance of goal-directed actions. Neurobiol Learn Mem 108:104-118.

Hawes SL, Evans RC, Unruh BA, Benkert EE, Gillani F, Dumas TC, Blackwell KT (2015) Multimodal plasticity in dorsal striatum while learning a lateralized navigation task. J Neurosci 35:10535-10549.

Hayashi-Takagi A, Takaki M, Graziane N, Seshadri S, Murdoch H, Dunlop AJ, Makino Y, Seshadri AJ, Ishizuka K, Srivastava DP, Xie Z, Baraban JM, Houslay MD, Tomoda T, Brandon NJ, Kamiya A, Yan Z, Penzes P, Sawa A (2010) Disrupted-in-schizophrenia 1 (DISC1) regulates spines of the glutamate synapse via Racl. Nat Neurosci 13:327-332.

Hayrapetyan V, Castro S, Sukharnikova T, Yu C, Cao X, Jiang YH, Yin HH (2014) Region-specific impairments in striatal synaptic transmission and impaired instrumental learning in a mouse model of angelman syndrome. Eur J Neurosci 39:1018-1025.

Hernandez-Lopez S, Tkatch T, Perez-Garci E, Galarraga E, Bargas J, Hamm H, Surmeier DJ (2000) D2 dopamine receptors in striatal medium spiny neurons reduce L-type $\mathrm{Ca}^{2+}$ currents and excitability via a novel PLC[beta] 1-IP3-calcineurin-signaling cascade. J Neurosci 20:8987-8995.

Hintiryan H, Foster NN, Bowman I, Bay M, Song MY, Gou L, Yamashita S, Bienkowski MS, Zingg B, Zhu M, Yang XW, Shih JC, Toga AW, Dong HW (2016) The mouse cortico-striatal projectome. Nat Neurosci 19:11001114.

Huber AB, Kania A, Tran TS, Gu C, De Marco Garcia N, Lieberam I, Johnson D, Jessell TM, Ginty DD, Kolodkin AL (2005) Distinct roles for secreted semaphorin signaling in spinal motor axon guidance. Neuron 48:949964.

Hutsler JJ, Zhang H (2010) Increased dendritic spine densities on cortical projection neurons in autism spectrum disorders. Brain Res 1309:83-94.

Jackman SL, Regehr WG (2017) The mechanisms and functions of synaptic facilitation. Neuron 94:447-464.

Jones EG, Coulter JD, Burton H, Porter R (1977) Cells of origin and terminal distribution of corticostriatal fibers arising in the sensory-motor cortex of monkeys. J Comp Neurol 173:53-80.

Kasanetz F, Riquelme LA, O'Donnell P, Murer MG (2006) Turning off cortical ensembles stops striatal up states and elicits phase perturbations in cortical and striatal slow oscillations in rat in vivo. J Physiol 577:97-113.

Kemp JM, Powell TP (1970) The cortico-striate projection in the monkey. Brain 93:525-546.

Kim IH, Racz B, Wang H, Burianek L, Weinberg R, Yasuda R, Wetsel WC, Soderling SH (2013) Disruption of Arp2/3 results in asymmetric structural plasticity of dendritic spines and progressive synaptic and behavioral abnormalities. J Neurosci 33:6081-6092.

Kim SA, Kim BN, Kim JW, Shin MS, Park TW, Son JW, Chung US, Park M (2017) Polymorphism in the promoter region of SEMA5A is associated with sociality traits in korean subjects with autism spectrum disorders. Psychiatry Investig 14:876-878.

Kozorovitskiy Y, Saunders A, Johnson CA, Lowell BB, Sabatini BL (2012) Recurrent network activity drives striatal synaptogenesis. Nature 485: $646-650$.

Kupferschmidt DA, Augustin SM, Johnson KA, Lovinger DM (2019) Active zone proteins RIM $1 \alpha \beta$ are required for normal corticostriatal transmission and action control. J Neurosci 39:1457-1470.

Levesque M, Charara A, Gagnon S, Parent A, Deschenes M (1996) Corticostriatal projections from layer $\mathrm{V}$ cells in rat are collaterals of long-range corticofugal axons. Brain Res 709:311-315.

Ludwar BCh, Evans CG, Jing J, Cropper EC (2009) Two distinct mechanisms mediate potentiating effects of depolarization on synaptic transmission. J Neurophysiol 102:1976-1983.

Mann F, Chauvet S, Rougon G (2007) Semaphorins in development and adult brain: implication for neurological diseases. Prog Neurobiol 82: $57-79$.

Marín O, Yaron A, Bagri A, Tessier-Lavigne M, Rubenstein JL (2001) Sorting of striatal and cortical interneurons regulated by semaphorinneuropilin interactions. Science 293:872-875.

McGeorge AJ, Faull RL (1989) The organization of the projection from the cerebral cortex to the striatum in rat. Neuroscience 29:503-537.

Morris RW, Quail S, Griffiths KR, Green MJ, Balleine BW (2015) Corticostriatal control of goal-directed action is impaired in schizophrenia. Biol Psychiatry 77:187-195.

Mosca-Boidron AL, Gueneau L, Huguet G, Goldenberg A, Henry C, Gigot N, Pallesi-Pocachard E, Falace A, Duplomb L, Thevenon J, Duffourd Y, StOnge J, Chambon P, Rivière JB, Thauvin-Robinet C, Callier P, Marle N, Payet M, Ragon C, Goubran Botros H, et al (2016) A de novo microdeletion of SEMA5A in a boy with autism spectrum disorder and intellectual disability. Eur J Hum Genet 24:838-843.

Nimchinsky EA, Sabatini BL, Svoboda K (2002) Structure and function of dendritic spines. Annu Rev Physiol 64:313-353.

Nisenbaum ES, Wilson CJ, Foehring RC, Surmeier DJ (1996) Isolation and characterization of a persistent potassium current in neostriatal neurons. J Neurophysiol 76:1180-1194.

Orr BO, Fetter RD, Davis GW (2017) Retrograde semaphorin-plexin signalling drives homeostatic synaptic plasticity. Nature 550:109-113.

Ostlund SB, Balleine BW (2005) Lesions of medial prefrontal cortex disrupt the acquisition but not the expression of goal-directed learning. J Neurosci 25:7763-7770.

Ouimet CC, Miller PE, Hemmings HC Jr, Walaas SI, Greengard P (1984) DARPP-32, a dopamine- and adenosine $3^{\prime}: 5^{\prime}$-monophosphate-regulated phosphoprotein enriched in dopamine-innervated brain regions. III. Immunocytochemical localization. J Neurosci 4:111-124.

Parent M, Parent A (2006) Single-axon tracing study of corticostriatal projections arising from primary motor cortex in primates. J Comp Neurol 496:202-213.

Pasterkamp RJ, Giger RJ (2009) Semaphorin function in neural plasticity and disease. Curr Opin Neurobiol 19:263-274

Peixoto RT, Wang W, Croney DM, Kozorovitskiy Y, Sabatini BL (2016) Early hyperactivity and precocious maturation of corticostriatal circuits in Shank3B(-/-) mice. Nat Neurosci 19:716-724.

Pennartz CM, Berke JD, Graybiel AM, Ito R, Lansink CS, van der Meer M, Redish AD, Smith KS, Voorn P (2009) Corticostriatal interactions during learning, memory processing, and decision making. J Neurosci 29: 12831-12838.

Penzes P, Cahill ME, Jones KA, VanLeeuwen JE, Woolfrey KM (2011) Dendritic spine pathology in neuropsychiatric disorders. Nat Neurosci 14: 285-293.

Portmann T, Yang M, Mao R, Panagiotakos G, Ellegood J, Dolen G, Bader, Patrick L, Grueter, Brad A, Goold C, Fisher E, Clifford K, Rengarajan P, Kalikhman D, Loureiro D, Saw NL, Zhengqui Z, Miller MA, Lerch JP, et al (2014) Behavioral abnormalities and circuit defects in the basal ganglia of a mouse model of 16p11.2 deletion syndrome. Cell Reports 7:1077-1092.

Ramakers GJ (2002) Rho proteins, mental retardation and the cellular basis of cognition. Trends Neurosci 25:191-199.

Reiner A, Jiao Y, Del Mar N, Laverghetta AV, Lei WL (2003) Differential morphology of pyramidal tract-type and intratelencephalically projectingtype corticostriatal neurons and their intrastriatal terminals in rats. J Comp Neurol 457:420-440.

Reiner A, Hart NM, Lei W, Deng Y (2010) Corticostriatal projection neurons-dichotomous types and dichotomous functions. Front Neuroanat $4: 142$.

Royce GJ (1982) Laminar origin of cortical neurons which project upon the caudate nucleus: a horseradish peroxidase investigation in the cat. J Comp Neurol 205:8-29.

Schneider Gasser EM, Straub CJ, Panzanelli P, Weinmann O, Sassoè- 
Pognetto M, Fritschy JM (2006) Immunofluorescence in brain sections: simultaneous detection of presynaptic and postsynaptic proteins in identified neurons. Nat Protoc 1:1887-1897.

Schubert D, Martens GJ, Kolk SM (2015) Molecular underpinnings of prefrontal cortex development in rodents provide insights into the etiology of neurodevelopmental disorders. Mol Psychiatry 20:795-809.

Shan Q, Ge M, Christie MJ, Balleine BW (2014) The acquisition of goaldirected actions generates opposing plasticity in direct and indirect pathways in dorsomedial striatum. J Neurosci 34:9196-9201.

Shen W, Hernandez-Lopez S, Tkatch T, Held JE, Surmeier DJ (2004) Kv1.2containing $\mathrm{K}+$ channels regulate subthreshold excitability of striatal medium spiny neurons. J Neurophysiol 91:1337-1349.

Shepherd GM (2013) Corticostriatal connectivity and its role in disease. Nat Rev Neurosci 14:278-291.

Shiflett MW, Balleine BW (2011) Molecular substrates of action control in cortico-striatal circuits. Prog Neurobiol 95:1-13.

Shiflett MW, Brown RA, Balleine BW (2010) Acquisition and performance of goal-directed instrumental actions depends on ERK signaling in distinct regions of dorsal striatum in rats. J Neurosci 30:2951-2959.

Shiflett MW, Gavin M, Tran TS (2015) Altered hippocampal-dependent memory and motor function in neuropilin 2-deficient mice. Transl Psychiatry $5: e 521$.

Shipp S (2017) The functional logic of corticostriatal connections. Brain Struct Funct 222:669-706.

Shu Y, Hasenstaub A, Duque A, Yu Y, McCormick DA (2006) Modulation of intracortical synaptic potentials by presynaptic somatic membrane potential. Nature 441:761-765.

Smith YG, Galvan A, Ellender TJ, Doig N, Villalba RM, Huerta-Ocampo I, Wichmann T, Bolam JP (2014) The thalamostriatal system in normal and diseased states. Front Syst Neurosci 8:5.

Sohur US, Padmanabhan HK, Kotchetkov IS, Menezes JR, Macklis JD (2014) Anatomic and molecular development of corticostriatal projection neurons in mice. Cereb Cortex 24:293-303.

Thorn CA, Atallah H, Howe M, Graybiel AM (2010) Differential dynamics of activity changes in dorsolateral and dorsomedial striatal loops during learning. Neuron 66:781-795.

Tran TS, Carlin E, Lin R, Martinez E, Johnson JE, Kaprielian Z (2013) Neuropilin 2 regulates the guidance of post-crossing spinal commissural axons in a substype-specific manner. Neural Dev 8:15.

Tran TS, Kolodkin AL, Bharadwaj R (2007) Semaphorin regulation of cellular morphology. Annu Rev Cell Dev Biol 23:263-292.
Tran TS, Rubio ME, Clem RL, Johnson D, Case L, Tessier-Lavigne M, Huganir RL, Ginty DD, Kolodkin AL (2009) Secreted semaphorins control spine distribution and morphogenesis in the postnatal CNS. Nature 462:1065-1069.

Veening JG, Cornelissen FM, Lieven PA (1980) The topical organization of the afferents to the caudatoputamen of the rat. A horseradish peroxidase study. Neuroscience 5:1253-1268.

Walz A, Rodriguez I, Mombaerts P (2002) Aberrant sensory innervation of the olfactory bulb in neuropilin-2 mutant mice. J Neurosci 22:40254035 .

Wang Q, Chiu SL, Koropouli E, Hong I, Mitchell S, Easwaran TP, Hamilton NR, Gustina AS, Zhu Q, Ginty DD, Huganir RL, Kolodkin AL (2017) Neuropilin-2/plexina3 receptors associate with GluA1 and mediate Sema3F-dependent homeostatic scaling in cortical neurons. Neuron 96:1084-1098.e7.

Wilson CJ (1987) Morphology and synaptic connections of crossed corticostriatal neurons in the rat. J Comp Neurol 263:567-580.

Wilson CJ (1993) The generation of natural firing patterns in neostriatal neurons. Prog Brain Res 99:277-297.

Wilson CJ (1995) Dynamic modification of dendritic cable properties and synaptic transmission by voltage-gated potassium channels. J Comput Neurosci 2:91-115.

Wu S, Yue W, Jia M, Ruan Y, Lu T, Gong X, Shuang M, Liu J, Yang X, Zhang D (2007) Association of the neuropilin-2 (NRP2) gene polymorphisms with autism in chinese han population. Am J Med Genet B Neuropsychiatr Genet 144B:492-495.

Yaron A, Huang PH, Cheng HJ, Tessier-Lavigne M (2005) Differential requirement for plexin-A3 and -A4 in mediating responses of sensory and sympathetic neurons to distinct class 3 semaphorins. Neuron 45:513-523.

Yin HH, Ostlund SB, Knowlton BJ, Balleine BW (2005) The role of the dorsomedial striatum in instrumental conditioning. Eur J Neurosci 22:513-523.

Yin HH, Mulcare SP, Hilário MR, Clouse E, Holloway T, Davis MI, Hansson AC, Lovinger DM, Costa RM (2009) Dynamic reorganization of striatal circuits during the acquisition and consolidation of a skill. Nat Neurosci $12: 333-341$

Yoshida Y (2012) Semaphorin signaling in vertebrate neural circuit assembly. Front Mol Neurosci 5:71.

Zbili M, Rama S, Debanne D (2016) Dynamic control of neurotransmitter release by presynaptic potential. Front Cell Neurosci 10:278. 